\title{
La economía del bien común y la economía social y solidaria, ¿son teorias complementarias?
}

\author{
Verónica Gómez Calvo \\ Rosario Gómez-Álvarez Díaz
}

\section{RESUMEN}

Nuestro propósito es determinar si existe complementariedad entre la Economía Social y Solidaria y la Economía del Bien Común pues ambas comparten el propósito de construir una economía basada en valores y con objetivos sociales. Una vez presentadas ambas teorías, se realiza una comparativa de los aspectos comunes: la visión antropológica del hombre, la democracia como principio de construcción desde lo local y el activismo. Por otro lado, se identifica las diferencias respecto a la empresa, el capital, el valor social, la amplitud de las relaciones mercantilistas y el papel del sector público. Nuestra conclusión es que ambas propuestas ofrecen aspectos complementarios para generar un proceso de transformación económico, político y social.

PALABRAS CLAVE: Bien común, economía social, solidaria, democracia, valores, bienes relacionales.

CLAVES ECONLIT: A13, P1, P52, P59.

Cómo citar este artículo / How to cite this article: GÓMEZ, V. \& GÓMEZ-ÁLVAREZ, R. (2016): "La economía del bien común y la economía social y solidaria, ¿son teorías complementarias?", CIRIEC-España, Revista de Economía Pública, Social y Cooperativa, 87, 257-294.

Correspondencia: Dra. Verónica Gómez Calvo, USAC-Universidad de Nevada, Reno (EEUU), e-mail: veronica.gomez@usac.unr.edu; Dra. Rosario Gómez-Álvarez Díaz, Universidad de Sevilla, España, e-mail: charogomez@us.es. 


\section{EXPANDED ABSTRACT}

\section{The economy for the common good and the social and solidarity economies, are they complementary?}

This paper analyzes 3 alternatives to the neoliberal capitalist system: The Social and Solidarity Economy and the Economy for the Common Good in order to identify what common characteristics they share, such as values and social objectives, as well as their differences. We also seek for those aspects that could complementary one another at different levels, such as the organization and business management, the markets function, the role of the State and the citizenship, all of them key factors to transform our present economy in an democratic, fair and sustainable alternative.

Today's global crisis is an environmental, economic, social and political crisis that has fuelled the academic debate around alternatives to the neoliberal system, and the practices of the social and solidarity economy as means to overcome these issues and transform our economic, social and political reality. This debate, in fact, has moved from the academic field into the political and legal arena. In 2009, The European Parliament passed a resolution on the Social and Solidarity Economy (SSE) in order to acknowledge and promote it. Afterwards, in 2015, The European Social and Economic Committee gave a favourable opinion on the Economy for the Common Good and the creation of a "European ethic market".

This is a theoretical study. On section 2, we introduce the main characteristics of the Social Economy first and then the Solidarity Economy, to end up explaining how they merge in a unique term: The Social and Solidarity Economy as well as what their practical proposals are to transform the economic system. On section 3, we focus on the Economy for the Common Good, starting with the definition of Common Good, we introduce later its main transformative proposals. On section 4, we identify the similarities and differences between these three - The Social and Solidarity Economy and the Economy for the Common Good-, and how they complementary each other at different levels. We end this paper with some conclusions on section 5 .

Multiple global crisis and heightened concerns about the social and environmental consequences of economic growth and liberalization have reignited interest in alternative production and consumption patterns and ways of organizing enterprise activities, with a considerable attention on Social and Solidarity Economy (SSE), which is used to refer to organizations and enterprises engaged in the production and exchange of goods and services that are autonomous from the state and guided by social objectives and values that place human well-being, cooperation and solidarity at their core. 


\section{LA ECONOMÍA DEL BIEN COMÚN Y LA ECONOMÍA SOCIAL Y SOLIDARIA, ¿SON TEORÍAS COMPLEMENTARIAS?}

These organizations include cooperatives, mutual associations, women's self-help groups, unions of informal economy workers, fair trade networks, and solidarity finance schemes. Many studies demonstrate that the SSE not only reduces the scope for negative social and environmental externalities associated with the conventional for-profit enterprise, but also fosters equitable patterns of resource and surplus distribution and promotes social, cultural and power relations that can be considered democratic, empowering and emancipatory.

On the other hand, the Economy for the Common Good has emerged in Europe as an alternative to replace an economic system that is running into fundamental structuring problems. Its founder, Christian Felber, seeks to address a capitalist system that creates a number of serious problems, such as unemployment, inequality, poverty, exclusion, hunger, environmental pollution and degradation and climate change. The ECG proposes an economic system that applies standards for human relationships as well as constitutional values to the economy in order to reward economic stakeholders for behaving and organizing themselves in a humane, cooperative, ecological and democratic way. For this purpose, five fundamental values: human dignity, cooperation and solidarity, ecological sustainability, social justice and democratic co-determination and transparency form the basis of the ECG model.

The ECG vision would be world changing and applies 20 utopian principles - including income caps, limitations on private wealth, and a move to nationalize natural resources to say a few. However, in the shorter range, the ECG activities are more pragmatic and attain to apply the Common Good Balance sheet to organizations and businesses. This balance sheet measures their contribution to these former five values and therefore, their contribution to the Common Good.

Businesses can make their Common Good Balance public, consumer awareness, nonetheless, in only one of the ECG targets, since it is necessary to get the administration involved in order to develop a system of economic benefits that awards sustainable and responsible organizations and enterprises against those that don't behave in an ethical and environmentally friendly way. In this regard, it is necessary to work locally and with grassroots groups, like the Solidarity Economy does, in order to create awareness and mobilize the public and politicians to change the predatory system we live today in for another that promotes human well-being. Politically and economically, the ECG is still on the fringes but it has already demonstrated its ability to draw together a partnership of companies, consumers and communities, and draw political attention. The SSE also works in line to receive the recognition and priority they deserve in national and international knowledge and policy circles. However, meaningful policy change requires a reconfiguration of social and political forces, coalitions and alliances as well as democratic governance arranges that enable effective participation of intended beneficiaries and their advocates.

As a result of this study we've found that the SSE and the ECG share the same economic vision, the economic system must work to serve human beings and their well being and must be based on social values and objectives to attain it. For both, the Solidarity Economy and the ECG, this goal can only be achieved through emancipation and empowerment of people. In the Solidarity Economy, thanks 
to the self-organization of citizens and their economic activities; in the ECG through the transformation of the representative democracy into a democracy that is also participatory and direct and places the system under democratic control. Both alternatives realize that this process involves a change in values first and for the most, and another way of thinking about economic activity.

The SSE has a longer tradition and a much broader field experience, while the ECG was created in 2010 with just one particular proposal. The SSE was originated to answer and solve immediate social problems, and the ECG thanks to the believe that is necessary to overcome today's economic predatory system with an alternative model that promotes human well being and is based on social values and objectives.

However, the SSE has very strict requirements for enterprises to be conceptualized as SSE businesses, while the ECG can host all different types of organizations and businesses, all of them can apply the Common Good Balance sheet (CGB), which works as a roadmap to re-direct their activities in line with the five ECG values that promote common good.

The Solidarity Economy believes there are numerous ways of organizing economically, and challenges the idea all development is like Western development, demanding taht only the people should decide what development means for them and how they want to develop. However, the ECG has created a tool that seeks to transform reality from inside the markets. Economic decisions are still based on the prices, but these prices assume the social costs derived from economic activities. The application of the CGB aligns the enterprise activity with social needs and objectives in a way that the CGB helps to create shared social value. In our view, these proposals are complementary, and the reform of the market proposed by the ECG would be the right place for the development of SSE initiatives.

Both, the SSE and the ECG need the intervention of the State, not to solve the problems created by the markets, but in order to co-create a different type of market, but this can be attained only through the strengthen of direct democracy, new spaces for self-organization and common goods management, the redefinition of the concept of private property, the design of new development policies, the change in the economic incentives for businesses and the market, and even a change in the operating parameters of the public sector itself.

As limitations, we believe the SSE has difficulties to reach all sectors of society and align them with their program, while the ECG needs the administration to get involved to change the economic incentives of businesses and the market. And maybe, the major challenge, for the SolE and the ECG, is to demonstrate the democratic principles can be a method to regulate the economic production and consumption of goods and services.

KEYWORDS: Common good, social economy, solidarity economy, democracy, values, relational goods. 


\section{1.- Introducción}

Desde el siglo XX existen diferentes corrientes que proponen teorías alternativas al sistema capitalista y que comparten dos evaluaciones. La primera es la crítica y oposición a la legitimación de la acumulación de beneficios como fin de la economía y no como medio. La segunda es la responsabilidad del sistema actual de la desigualdad, la insostenibilidad ecológica, la inestabilidad financiera y la crisis de estado de bienestar.

Estas propuestas reclaman un modelo económico distinto, que tenga como objetivo prioritario el bienestar de las personas. Una de las más conocidas es la teoría del Desarrollo Humano de Amartya Sen (1981, 1999), la cual afirma que la verdadera riqueza de un país está en la ampliación de la libertad real de las personas para poder elegir el tipo de vida digna que desean tener. Por su parte, Max-Neef (1994) afirma que las necesidades son limitadas, pero los medios para satisfacerlos no. Por ello reivindica una economía a escala humana, acorde con el mundo finito en el que vivimos, de forma que la economía es un parte de la vida humana, y por tanto es interdependiente con el resto de elementos culturales, sociales, políticos, y también medioambientales (Georgescu-Roegen, 1971; Naredo, 2003). Esa interdependencia también es explícita en más teorías, como la propuesta decrecionista que plantea la necesidad de vivir con menos (Latouche,1991, 2009) o la economía del buen vivir que demanda una sistema económico que permita una vida en armonía con uno mismo, el resto de la sociedad y la naturaleza (Acosta et ál. 2011). Por otra parte, el ecofeminismo (Herrero, 2011) ofrece un papel fundamental de la mujer en una economía sostenible, con aspectos comunes con la economía de los cuidados (Carrasco, 2011), donde se destaca la importancia del trabajo reproductivo, y del cuidado a los demás como prioridad social, estando la economía productiva al servicio de la primera y no al revés.

Pues bien, dentro de estas corrientes económicas alternativas, cuyo fin último es la vida de las personas y no el volumen de producción, nos centramos en la Economía Social y Solidaria (ESS) y la Economía del Bien Común (EBC). Ambas comparten la defensa de los valores como principio básico para el desenvolviendo de las relaciones económicas y para el cambio social, frente al principio del egoísmo y la maximización de los beneficios.

En concreto, la ESS plantea la transformación social, mediante el principio de la solidaridad y la democratización de la economía (Razeto, 1994; Laville, 2004). Por su parte, la EBC (Felber, 2012), reclama que sea el bien común, entendido como los valores de la dignidad, la solidaridad, la justicia social, la sostenibilidad medioambiental y la democracia, la medida del éxito económico. Añade que para ello es necesario basar el sistema económico en la cooperación, al igual que la ESS, y que el mercado sea rediseñado para que los intereses personales también promuevan el bien común. Tanto en el 
caso de la EBC como en la ESS, la participación democrática es el catalizador de la transformación social, compartiendo el activismo político que se concreta en organizaciones internacionales, a partir de una articulación local descentralizada, con la puesta en marcha de proyectos reales y viables.

La combinación de reflexión teórica y realidad práctica ha propiciado que ocupen un lugar destacado en los debates académicos, sociales y políticos, así como en la generación de medios para la búsqueda de otros modelos económicos, trascendiendo incluso al ámbito legal. En concreto, en Europa, el Parlamento Europeo aprobó en el 2009 una resolución sobre la Economía Social, que incluía a la Economía Solidaria, para su Reconocimiento y Fomento. Posteriormente, en 2015, el Comité Económico y Social Europeo realizó un dictamen favorable para el fomento de las propuestas de la Economía del Bien Común, defendiendo la creación de un "mercado ético europeo".

Nos planteamos como objetivo central el análisis de cuáles son las principales diferencias de cada una de estas corrientes, y si éstas son complementarias para construir otra economía. Una vez presentada ambas teorías, se realiza una comparativa de los aspectos comunes: visión antropológica del hombre, la democracia como principio de construcción desde lo local y el activismo. Por otro lado, se identifica las diferencias respecto a la empresa, el capital, el valor social, la amplitud de las relaciones mercantilistas y el papel del sector público. Nuestra conclusión es que ambas propuestas ofrecen aspectos complementarios para generar un proceso de transformación económico, político y social.

En este trabajo, en el apartado 2, presentamos las principales características, por un lado de la Economía Social (ES), por otro de la Economía Solidaria (ESol), y explicamos su confluencia en un único término, la Economía Social y Solidaria, así como sus propuestas concretas de transformación del sistema económico. En el apartado 3, nos centramos en la Economía del Bien Común, partiendo de la delimitación del concepto del bien común, y presentamos sus principales propuestas. En el apartado 4 identificamos las similitudes y las diferencias, y si éstas son elementos de complementariedad, finalizando con las conclusiones en el apartado 5.

\section{2.- La economía social y solidaria}

\subsection{La Economía Social}

La cooperación como elemento fundamental de la actividad económica aparece explícitamente en los análisis teóricos en las obras de diversos autores del siglo XVII llamados asociacionistas, en la economía civil italiana del siglo XVIII de la mano de Genovesi (Zamagni y Bruni, 2007), y en el siglo XIX con las obras de Sismonde, Saint-Simon, Owen, John Stuart Mill, (Gómez y Gómez-Alvarez, 2015) 


\section{LA ECONOMÍA DEL BIEN COMÚN Y LA ECONOMÍA SOCIAL Y SOLIDARIA, ¿SON TEORÍAS COMPLEMENTARIAS?}

o Walrras (Pérez, Etxezarreta y Guridi, 2009). De igual forma, las iniciativas económicas reales basadas en la cooperación están presentes en todas las épocas y las civilizaciones bajo la forma de asociaciones y mutualidades, pero no es hasta el siglo XIX cuando aparece la figura jurídica de las empresas cooperativas en el derecho societario (Monzón, 2003). En concreto, en 1895 se crea en Londres la Alianza Cooperativa Internacional, en la que se recogen los valores y principios básicos del movimiento cooperativo vigentes hasta ahora.

Estos inspiraron la aparición del concepto del Economía Social en los años 80, propuesto por las cooperativas, mutualidades y asociaciones, y si bien aparecen diferentes definiciones según el ámbito territorial y la organización, debido a diferencias socio-históricas, comparten una serie de principios comunes. ${ }^{1}$ La propuesta más reciente procede de la Social Economy Europe (SEE) en 2002, e identifica a las organizaciones de la ES como aquellas que se rigen por unos principios básicos como son (Monzón y Chaves, 2012):

I. Prioridad de la persona y del objeto social por encima del capital,

II. adhesión voluntaria y abierta,

III. control democrático ejercido por sus miembros,

IV. combinación de los intereses de los miembros usuarios y/o del interés general;

V. defensa y aplicación de los principios de solidaridad y responsabilidad,

VI. autonomía de gestión e independencia respecto de los poderes públicos,

VII. utilización de la mayoría de los excedentes para la consecución de objetivos a favor del desarrollo sostenible, los servicios de interés para los miembros y el interés general.

Esta propuesta es la base de la definición del Comité Económico y Social (Chaves y Monzón, 2012), considerada con mayor aval institucional, y empleada para la metodología de los sistemas de contabilidad de Economía Social (SEC-1995 y SCN-2008). En concreto, la ES es el:

"Conjunto de empresas privadas organizadas formalmente, con autonomía de decisión y libertad de adhesión, creadas para satisfacer las necesidades de sus socios a través del mercado, produciendo bienes y servicios, asegurando o financiando y en las que la eventual distribución entre los socios de beneficios o excedentes así como la toma de decisiones, no están ligados directamente con el capital o cotizaciones aportados por cada socio, correspondiendo un voto a cada uno de ellos. La Economía Social también agrupa a aquellas entidades privadas organizadas formalmente con autonomía de decisión y libertad de adhesión que producen servicios de no mercado a favor de las familias, cuyos excedentes, si los hubiera, no pueden ser apropiados por los agentes económicos que las crean, controlan o financian".

1.- Consultar CIRIEC es una organización no gubernamental de carácter científico con delegaciones nacionales en diferentes países, que es el principal referente de la ES http://www.ciriec.ulg.ac.be/en/pages/1_Ociriec.htm 
Dentro de la ES, se distinguen dos grandes subsectores el de mercado y el de no mercado, recogidos en la Contabilidad Nacional (Monzón, 2006).

a) El subsector de mercado o empresarial, los requisitos son los siguientes:

- Se crean para satisfacer las necesidades de sus socios, habitualmente se da la condición de ser socio y usuario a la vez.

- Son productores de mercado, en el sentido de que operan en él, vendiendo productos a precios significativos y de él obtienen la mayoría de sus recursos.

- Pueden distribuir excedentes entre sus socios-usuarios, pero no en proporción al capital, sino de acuerdo con la actividad que cada uno desempeña.

Dentro de este grupo se contemplan las empresas de la economía social: cooperativas, mutuas, las empresas de inserción laboral, y las sociedades laborales o de responsabilidad limitada, siempre que la mayoría del capital sea de los socios-trabajadores.

b) El subsector de productores no de mercado se caracteriza por:

- La producción de bienes y servicios de no mercado a favor de las familias.

- No son productores de mercado, por lo que sus recursos monetarios provienen principalmente de fuentes externas al mercado: donaciones, cuotas de socios, subvenciones,etc. La producción se suministra de forma gratuita o con precios económicamente no significativos.

- Los excedentes, si los hubiera, no pueden ser apropiados por los agentes que los crean, controlan o financian.

- La mayoría de las organizaciones de esta tipología son fundaciones y asociaciones, que han experimentado una proliferación y aumento en la provisión de los servicios públicos.

Fajardo (2012:71) destaca que la nota característica de la economía social no es tanto la actividad económica que desarrolla sino el modo de desarrollarla y el fin perseguido con la misma, como se deduce de sus principios. Así, una característica determinante de las entidades de la economía social, es el empleo de procesos democráticos y participativos de decisión, donde cada persona es un voto, independientemente de su aportación al capital. ${ }^{2}$

Junto a un modo diferente de gestión de la empresa capitalista, el otro elemento definitorio es el interés común de servicio a sus socios, de servicio al interés general, o ambos. De hecho, ejercen una actividad económica en sí misma considerada para satisfacer necesidades de personas, hogares 0 familias; por eso se dice que las organizaciones de economía social son entidades de personas. Trabajan con capital y otros recursos no monetarios, pero no para el capital (Monzón, 2013:80).

2.- El manual de las cuenta satélite de la Comisión considera este criterio fundamental en la delimitación de la ES, si bien ha permitido la inclusión de organizaciones a entidades voluntarias no lucrativas, aún cuando no posean esta característica, justificada por la producción de bienes no de mercado de utilidad social a favor de familias. 


\section{LA ECONOMÍA DEL BIEN COMÚN Y LA ECONOMÍA SOCIAL Y SOLIDARIA, ¿SON TEORÍAS COMPLEMENTARIAS?}

Estas empresas y organizaciones desarrollan su actividad entre la economía pública y la economía capitalista tradicional, combinando múltiples recursos mercantiles y no mercantiles que van desde donaciones filantrópicas, subvenciones del Estado, e ingresos mercantiles, hasta el trabajo voluntario y el remunerado. De esta manera, integran la lógica del mercado junto a la solidaridad y la redistribución.

La ES ha sido capaz de articular un discurso teórico y práctico de que es posible la democratización de la sociedad civil en la esfera de la actividad productiva de la empresa y crear espacios económicos, basados en la libertad y solidaridad para aquellos excluidos por el sector privado y público. Además cuenta con un desarrollo institucional importante en algunos países, con un nivel de consenso bastante elevado entre los agentes que lo conforman y lo estudian y con organizaciones reconocidas a nivel mundial como es el caso de CIRIEC (Monzón, 2013; Chaves y Demoustier, 2013; Fajardo, 2012).

No obstante, existen, dos debates. El primero de ellos es la aparición de nuevas formas de gestión empresarial, donde existe un claro objetivo social en su labor, pero no hay acuerdo sobre si es adecuada su inclusión o no como es el caso de las empresas sociales y su traslación a la legislación de los diferentes países (Fajardo, 2012; Defourny, J. y Nyssens, M., 2012).

El segundo debate es el cumplimientos de los principios de la ES por las organizaciones en su gestión y en sus relaciones de mercado, más allá de la forma jurídica. Así, en el caso de las mutualidades, y con todos los matices que caracterizan a cada estado, la generalización de los seguros sociales las ha convertido en organizaciones "para-estatales", perdiendo en el camino su carácter de filiación voluntaria y su independencia respecto de los poderes públicos. En otros casos, la inmersión en la economía mercantil y la competencia en los mercados con empresas de capital, ha generado un desequilibrio en el balance de sus objetivos y sus formas organizativas. A través de un proceso que Di Maggio y Powell (1983) denominan "isomorfismo mercantil", estas cooperativas han ido acercándose a la lógica del capital y la maximización del retorno a sus propietarios en detrimento de la filosofía fundacional del cooperativismo.

\subsection{La Economía Social y Solidaria}

\subsubsection{El enfoque de la economía solidaria}

La ES volvió a resurgir con fuerza en los años 70 debido a la crisis del Estado de Bienestar, la falta de empleo, y el riesgo de exclusión del mercado de trabajo. Esta situación originó formas dinámicas de autoempleo y reforzó la solidaridad entre los actores económicos para hacer frente a las nuevas necesidades 0 aquellas que no podían ser satisfechas, principalmente, las de las poblaciones más desfavorecidas. Los ámbitos fundamentales en los que surgen son la reinserción laboral de personas desplazadas del mercado laboral por diferentes motivos (Borzaga y Defourny, 2004) y el ámbito 
de los servicios sociales o de los cuidados comunitarios y personales, también llamados servicios de proximidad (Laville, 1994).

Desde entonces han ido apareciendo instituciones que adoptan diversas formas jurídicas y organizativas, a veces distintas de las formas clásicas de la ES y surgiendo nuevas relaciones económicas, tanto en el contexto europeo como sudamericano, todas ellas caracterizadas por intentar atender nuevas demandas sociales y su intención de transformación social (Monzón y Chaves, 2012).

En este contexto, la economía solidaria (ESol) se desarrolla en tres ámbitos complementarios (Coraggio, 2012, 2011; Guerra 2010, 2011; Martínez y Álvarez, 2008): como un paradigma teórico alternativo al capitalismo, una propuesta de transformación social y un modelo de empresa basada en la democracia, la autogestión y el empresariado colectivo. En este sentido, es pertinente el modelo explicativo de Defourny, Devertele y Fonteneau (1999), donde la economía solidaria es tanto una respuesta a las nuevas condiciones impuestas por el contexto de desempleo y exclusión creciente (necesidad), como también un proyecto de actores sociales implicados en la búsqueda de alternativas al modelo económico dominante (identidad).

Por un lado, La ESol es un marco teórico interesado en construir un paradigma alternativo sobre la economía neoclásica, partiendo de dos críticas. La primera de ellas es el rechazo al paradigma convencional del homo economicus (maximizador de utilidad, racional, individualista, atomizado y competitivo), y reivindica una visión del hombre con una pluralidad de motivaciones y de principios económicos de comportamiento (intercambio, redistribución y reciprocidad) y tres ámbitos donde cada una de ellos es predominante, aunque no exclusivo (mercado, estado y sociedad civil) (Polanyi, 2007). La segunda cuestiona la idea de la economía como una ciencia formalista e independiente del resto de la actividad social (Dash 2013; Coraggio 2009, 2011). Los teóricos de la ESol opinan que esta aproximación limita la comprensión de la economía en su conjunto en la medida en que: i) autonomiza la esfera económica asimilándola únicamente al mercado; ii) identifica el mercado como un mercado auto-regulado, y por tanto, ajeno a cualquier estructura institucional que la regule, y; iii) identifica la empresa moderna con la empresa capitalista, excluyendo del análisis a cualquier organización económica no-capitalista (Laville, 2004).

La ESol interpreta el mercado en el contexto de unas instituciones sociales (entendidas como estructuras pero también como normas de regulación) que lo moldean y lo sustentan, y se parte desde la base de que las relaciones económicas suceden de forma institucionalizada, y no como consecuencia de la búsqueda de un interés individual. La visión de la economía desde esta corriente es muy precisa en estas palabras de Razeto (2015:137): "No hay un solo elemento de la economía, por simple y pequeño que sea, que no constituya al mismo tiempo realidad ecológica, política, social y cultural. (...) Podemos expresar esto diciendo que no se trata de "niveles" superpuestos sino de "dimensiones" inherentes y constituyentes de la realidad, co-presentes en cada uno de sus elementos y articulados en el conjunto." 


\section{LA ECONOMÍA DEL BIEN COMÚN Y LA ECONOMÍA SOCIAL Y SOLIDARIA, ¿SON TEORÍAS COMPLEMENTARIAS?}

Por otro, la ESol es una propuesta de transformación social que tiene como objetivo eliminar la división teórica y práctica entre economía, sociedad y política. Así, Laville define a la ESol como "el conjunto de las actividades que contribuyen a la democratización de la economía a partir de compromisos ciudadanos" (Laville, 1994:127), de forma que es una búsqueda teórica y práctica de formas alternativas de hacer economía, basadas en la solidaridad y el trabajo (Luis Razeto, 1984).

Desde esos presupuestos, la ESol surge como un proyecto económico integral y a la vez un proyecto político alternativo, de tal forma que es imposible no ser económica (entendiendo la economía desde una visión plural) ni puede ser apolítica o acrítica políticamente (Laville, 2004; Coraggio, 2007; Arruda, 2005; Guerra, 2011).

Ese proyecto de unificación se produce en dos niveles. En el ámbito económico, la sociedad civil, junto al mercado y al sector público, cobra relevancia, pues es capaz de articular nuevas formas de producción, distribución y consumo mediante el ejercicio de la reciprocidad (Polanyi, 2007, Razzeto, 1994). Por otra parte, la sociedad civil en la esfera política reivindica otro tipo de democracia y otro tipo de economía, gracias a la presencia del activismo asociativo (Favureu, Lachapelle y Lorose, 2003). Sin embargo se debe reseñar que la ESol aparece en Latinoamérica (Razeto, 1984; Singer, 2009, Gaiger, 2007, Coraggio, 2007), como parte de una realidad de movimientos sociales y obreros, con una mayor vocación transformadora y alternativa al neoliberalismo que la corriente europea, que la considera compatible con el mercado y el estado (Pérez de Mendiguren, Etxezarreta y Guridi, 2009:1).

Por último, la ESol se identifica con un tipo específico de empresa basada en la democracia, la autogestión y el empresariado colectivo (Martínez y Álvarez, 2008), y que busca funcionar con una lógica diferente a las de las organizaciones mercantiles tradicionales. Estas nuevas formas empresariales son distintas a las entidades no lucrativas en función de su vocación de transformación social y su composición interna (Etxerrazeta y Morandeira, 2012). Estas organizaciones muestran un perfil político más activo, creando redes a partir de colectivos hetereogéneos (Laville, 2004) para crear entidades de naturaleza híbrida (Evers y Laville, 2004) pues emplean recursos monetarios y no monetarios y cuentan, en la mayoría de los casos con el voluntariado, junto a los trabajadores. En este sentido, muchas de las organizaciones o empresas de que se identifican como de Economía Solidaria, adoptan discursos y formas institucionales típicas de la Economía Social clásica (cooperativas, mutuales y asociaciones) aunque no exclusivamente. El estudio microeconómico del comportamiento de este tipo de organizaciones da lugar a una línea concreta de investigación teórico y práctico en torno a la denominada Empresa Social, cuya característica diferenciadora es que su objetivo empresarial específico es la resolución de un problema social (Pérez de Mendiguren, Etxezarreta y Guridi, 2009).

En definitiva, la ESol es un marco teórico para el desarrollo de un proyecto real de transformación en la esfera política, económica y social "que se presenta como una alternativa al modelo capitalista y busca, la democratización de la economía y la sustitución de la competencia por la cooperación, al tiempo que procura expandir los mecanismos políticos de participación" (Singer, 2009). 
Por ello "Frente a la lógica del capital, la mercantilización creciente de las esferas públicas y privadas y la búsqueda de máximo beneficio, la Economía Solidaria persigue construir relaciones de producción, distribución, consumo y financiación basadas en la justicia, la cooperación, la reciprocidad y la ayuda mutua. Frente al capital y su acumulación, la Economía Solidaria aboga por situar a las personas y su trabajo en el centro del sistema económico, otorgando a los mercados un papel instrumental siempre al servicio del bienestar de todas las personas y de la reproducción de la vida en el planeta" (Pérez de Mendiguren, Etxezarreta y Guridi, 2009:13).

\subsubsection{La Economía Social, y también Solidaria}

Todas estas experiencias reales y de conocimiento fructifican en muchos lugares del mundo, que van tejiendo diferentes redes asociativas, y que cuentan en la actualidad con una red de redes intercontinental que las vincula, la RIPESS. De estos procesos surge el término Economía Social y Solidaria como amalgama de estos dos conceptos, que como hemos visto en los párrafos anteriores, no son palabras sinónimas. ${ }^{3}$ En este sentido, Laville y García (2009) proponen utilizarlo para contextualizar su uso desde una perspectiva doblemente crítica: i) con de las derivas organizativas ocurridas en el seno de la Economía Social clásica, generalmente asociadas al crecimiento organizativo, y a la adopción de discursos sobre la eficiencia y la rentabilidad en detrimento de la democracia y la transformación social; ii) con el propio sistema capitalista, sus procesos y el papel fundamental que debe jugar la Economía Social. En este sentido, el concepto de ESS debería entenderse como parte del proceso de construcción de una alternativa postcapitalista.

En su carta de principios de la Economía Social y Solidaria se especifica (RIPPES, 2013):

"Sostenemos que la Economía Social y Solidaria está basada en valores humanos y principios de solidaridad, que propugnan el reconocimiento del otro como fundamento de la acción humana y fuente de la renovación de la política, la economía y la sociedad. La Economía Social y Solidaria incluye todas las actividades y organizaciones de carácter comunitario, asociativo, cooperativo y mutualista creadas para responder a las necesidades desempleo y de bienestar de los pueblos, así como a movimientos ciudadanos orientados a democratizar y transformar la economía".

En la misma carta, se declara como objetivo que la gestión de la actividad económica sea guiada por los valores universales que deben regir la sociedad y las relaciones entre los ciudadanos: equidad, justicia, fraternidad económica, solidaridad social y democracia directa. Estos valores éticos, sirven de guía a las personas y la construcción de la ESS que se fundamenta en seis principios: equidad, trabajo, sostenibilidad ambiental, cooperación, sin ánimo de lucro y compromiso con el entorno. Asimismo, junto a los valores y los principios, cabe destacar que las organizaciones que pertenecen al movimiento de la ESS comparten los ejes transversales de autonomía, autogestión, cultura libera-

3.- Para ver un análisis más detallado sobre el recorrido histórico, significación, uso y relación entre ellos se puede Pérez de Mendiguren, J. C y Etxezarreta, E, (2015). 


\section{LA ECONOMÍA DEL BIEN COMÚN Y LA ECONOMÍA SOCIAL Y SOLIDARIA, ¿SON TEORÍAS COMPLEMENTARIAS?}

dora, desarrollo humano, compenetración con la naturaleza, y solidaridad humana y económica (Defourny; Develtere y Fonteneau, 1999).

El discurso central, organizado en torno a la solidaridad, adquiere una centralidad fundamental que no se asumió de forma explícita y decisiva dentro del cooperativismo tradicional. En este sentido, Bocayuva nos señala que la solidaridad "no es solamente cómo cada sujeto organiza su empresa" y sí la forma como políticamente esos sujetos se articulan. Y esto, nos dice, es lo que explica que la economía solidaria sea una punta de "la inseparabilidad entre economía y políticas en este momento del embate concreto en esta sociedad". La economía solidaria, continúa, "va más allá de construir el cooperativismo y, en este sentido, tiene que ver con la plataforma y con la bandera política en el rediseño de la política industrial, de ciencia y tecnología, etc." (Bocayuva, 2000: 27).

\subsection{El proyecto de sociedad de la ESS}

La articulación de los valores y los principios propuestos se traducen en una serie de elementos básicos que están presentes en el proyecto social de la ESS como son (Faureau y Vaillancourt, 2001; Martín y Álvarez, 2008):

- La recuperación de la dimensión humana en la economía. El centro de las relaciones es la persona, por lo que el objetivo de toda economía es la satisfacción de las necesidades básicas, eliminando las bolsas de pobreza y exclusión social, y aumentando el bienestar de todos, anteponiendo el trabajo al capital, y basados en la solidaridad.

- Todas las actividades económicas han de ser ecológicas y socialmente sostenibles.

- Dichas actividades deben ser igualitarias y no discriminatorias y sujetas a las decisiones políticas de la comunidad, basadas en la democracia.

\subsubsection{La recuperación de la dimensión humana en la economía}

La ESS rechaza que el objetivo de la economía sea la acumulación de riqueza y el capital y la sustituye por la satisfacción de las necesidades, de forma que la economía debe estar al servicio de las personas y no al revés, con el objetivo de que los procesos económicos sean los medios para el desarrollo humano, entendido como un proceso multidimensional de la persona que vive en sociedad. De hecho, las experiencias de la ESS incorporan una serie de valores, como son la equidad, trabajo, sostenibilidad ambiental, cooperación, sin ánimo de lucro y compromiso con el entorno, como comentábamos en un párrafo anterior.

En la fase de la producción, las empresas y las organizaciones de la ESS reivindican la actividad económica como un medio al servicio de las personas y de la comunidad en la que se desarrollan. Se trata de empresas que, partiendo de la necesaria rentabilidad, eficacia y sostenibilidad técnica y financiera, no buscan la maximización de beneficios, y centran sus esfuerzos en el desarrollo de las personas trabajadoras, estando entre sus preocupación los efectos sociales y ambientales producidos en 
la consecución de sus objetivos. Una visión de la empresa, por tanto, que orienta su sentido y finalidad hacia el beneficio social y hacia la calidad de vida y desarrollo de las personas. Como no podía ser de otra forma, este tipo de empresas priorizan en su gestión aspectos como el fomento de la autonomía y la igualdad, la participación y la actividad cooperativa, el establecimiento de escalas salariales justas y proporcionales, la transparencia y auditoría social, la sostenibilidad medioambiental y social, etc. Actividades empresariales sin ánimo de lucro, donde no existe reparto de beneficios entre accionistas, sino que de haberlos se reinvierten en la creación de nuevos empleos, la mejora de su estructura técnica y el apoyo a nuevos emprendimientos de carácter socialmente beneficioso (Askunze, 2013).

En relación a la distribución y consumo, la Economía Social y Solidaria prioriza el ámbito local, como espacio natural, aunque no único, para el desarrollo de las relaciones humanas y de los procesos democráticos. De este planteamiento surgen las prácticas de cooperativas de consumo responsable, el comercio justo, los mercados sociales o las monedas sociales, que permiten ejercer otra forma de consumo. Las personas consumidoras pueden, a través de sus gestos cotidianos, contribuir al cambio de las reglas de producción y consumo en nuestra sociedad. En esos gestos y en la propia capacidad de elección, pueden convertir su acto de consumo en un acto de transformación social (Crespo y Sabín, 2014).

Asimismo, en el ahorro, las finanzas solidarias han mostrado que es rentable económicamente y socialmente otro tipo de uso del dinero. Se han desarrollado diversas formas de intermediación financiera: préstamos solidarios, gestión de microcréditos de carácter social, etc cobrando especial relevancia las instituciones bancarias organizadas por la ciudadanía para ofrecer los servicios de la banca tradicional con criterios éticos y socialmente responsables. De esta manera, son ya varias las experiencias de Banca Ética que operan a nivel local e internacional (Sasia, 2012).

En definitiva, la ESS entiende que la economía tiene tal variedad de sujetos, procesos y actividades, así como la solidaridad tiene tantas maneras de manifestarse, que no hay un único modo definido de modelo, de forma que estos valores y principios se despliegan en todas las funciones del mercado: producción, distribución, el consumo y el uso del dinero (Askuzen,2013).

\subsubsection{La sostenibilidad social y ecológica}

La ESS incorpora una mirada holística a la economía pues tiene que estar al servicio de la vida, y por tanto de la sostenibilidad social y ecológica.

La economía feminista, la ecología y la economía de los cuidados, han sido los marcos teóricos en los que se sustenta esta visión de la sostenibilidad. Desde esta perspectiva se hace necesaria una reorganización del trabajo remunerado para que todas las personas tengan acceso a un nivel suficiente de ingresos, y del reparto de las actividades reproductivas, como el cuidado doméstico, el voluntariado, el trabajo comunitario, etc. Por tanto, el concepto de trabajo se redefine y se amplía a todas 


\section{LA ECONOMÍA DEL BIEN COMÚN Y LA ECONOMÍA SOCIAL Y SOLIDARIA, ¿SON TEORÍAS COMPLEMENTARIAS?}

las actividades que favorecen y son parte del bienestar de las personas, más allá de las actividades económicas del mercado y del sector público, insertas todas ellas dentro de un sistema ecológico (Herrero, 2012).

Como consecuencia, el valor de los bienes y servicios generados deben tener en cuenta, además de su utilidad para satisfacer las necesidades, las condiciones ecológicas y sociales en las que se han producido, intercambiado y consumido (Coraggio, 2009). En opinión de este mismo autor, ni el mercado ni la planificación centralizada cuenta con mecanismos para incorporar este valor directamente, pero la ESS, por medio de las prácticas como el comercio justo o las finanzas éticas intentan evaluar dichos efectos.

Las variables económicas, tales como el precio, la calidad, la empleabilidad, el nivel salarial, etc. que en la economía mercantil o administrada, aparecen como una restricción externa e impuesta a los actores económicos, están más sujetas a debate en las iniciativas de la ESS. Por ejemplo, en los Sistemas de Intercambio Locales (SEL) la regulación de los créditos y deudas acumuladas por los miembros no se realiza a través de un banco central o prestamista, sino por un colectivo en debate. En las finanzas solidarias, los ahorradores se preocupan por saber para qué y cómo se invierten sus ahorros desde un sentimiento de solidaridad y ética. El Comercio Justo tiene como objetivos la búsqueda del precio "justo", y cierta reciprocidad en el intercambio, ya que hay un interés y se da a conocer la proveniencia, los modos de producción, y el precio al que se producen y comercializan estos productos. Estos son sólo algunos ejemplos que dan cuenta de lo importante que es la deliberación colectiva, y como mediante ésta se incorporan otros elementos de la organización económica no mercantilista.

\subsubsection{La democratización de la economía, desde lo local y desde abajo}

Para entender el éxito de estas buenas prácticas se debe tener en cuenta que se articulan por medio de las relaciones sociales fundamentadas en procesos democráticos y asamblearios, y el individuo ejerce su propia libertad y autonomía, por ello se hace preciso las relaciones de proximidad y el arraigo local.

Las prácticas de la Economía Solidaria, se incluyen dentro del ámbito del desarrollo local concebido por Alves da Silva (2006: 220) como "un proceso endógeno de movilización de las capacidades (humanas, sociales, políticas y culturales) y aprovechamiento de las potencialidades económicas locales, con la finalidad de la mejoría de las condiciones de vida de la población, en armonía con el medio ambiente".

En contraste, el sistema económico actual pone al hombre al servicio del sistema económico y no al revés. Según Vázquez (2000:26) y Gallicchio (2004:2), el modelo de desarrollo local es un modelo alternativo al modelo exógeno actual. Éste se concentra territorial e inequitativamente, se extrapola además, sin tener en cuenta el territorio, los recursos, la cultura, los saberes tradicionales, las institu- 
ciones, etc., en el que se inserta; por lo que no es posible aprovechar el potencial productivo de los distintos territorios, contribuyendo con ello, al aumento de la pobreza, pues se pierden saberes y potencialidades del lugar al aceptar desarrollarse a través de un modelo exógeno. Este modelo además, desposee a los individuos y colectivos de toda capacidad para tomar decisiones económicas, puesto que éstas son tomadas por agentes externos al área local, mientras que en los patrones de desarrollo endógeno las variables son controladas por los mismos agentes interesados.

Garafoli (1992:3) destaca que en el desarrollo local, el territorio se contempla como un factor estratégico decisivo, puesto que son sus características específicas las que facilitan las oportunidades de desarrollo, y los mismos representantes territoriales poseen una serie de características culturales locales que imprimen un sello de diferenciación en el contexto del desarrollo local. El desarrollo exógeno pasa por alto un conjunto de recursos naturales, económicos, humanos e institucionales que no son aprovechados y que en realidad constituyen su potencial, creando además en los territorios procesos de desestructuración económica y social supeditados a la acumulación de capital.

Como bien señalan Martínez y Álvarez (2008), las energías transformadoras se dan fundamentalmente en los espacios a escala humana donde la persona tiene presencia real. La proximidad permite detectar y diagnosticar, mediante la participación, necesidades y debilidades para determinar la orientación de la economía. Además, la ESS se organiza en redes horizontales construyendo cadenas productivas, auto-gestionándose y apoyándose en el principio de solidaridad.

Otro principio fundamental es el de subsidiaridad, es decir todo lo que se puede realizar a nivel pequeño, desde abajo, debe ser resuelto en ese ámbito, pero a la vez, se debe traspasar a un nivel superior aquellas cuestiones que involucren a espacios más amplios. Este principio, junto al de solidaridad conforma la base de una democracia económica y democracia política. La actividad económica se ha sustraído de los principios democráticos, sin embargo, en la ESS subyace una crítica constructiva al modelo actual que le circunda, proponiendo no sólo modelos económicos alternativos sino además buscando el reconocimiento de los modos de regulación democrática y ciudadana de las actividades económicas junto a las regulaciones del mercado y del Estado (Laville, 1994:127).

Además, puesto que las iniciativas de la ESS se rigen bajo criterios y valores sociales, necesitan del apoyo indispensable de políticas públicas concretas que les proteja frente a la libre competencia del sector privado. Sin estas políticas públicas de apoyo, estas propuestas alternativas no pueden sobrevivir a largo plazo en un contexto de competencia salvaje como el actual. Esta es una de las razones por las cuáles la ESS demanda la inclusión de cláusulas sociales de forma que se evalúen una serie de criterios sociales (discriminación positiva de las mujeres, respeto medioambiental, inserción sociolaboral,...) en los procesos de contratación pública, de cara a favorecer la responsabilidad social de las empresas y la promoción de las entidades de ESS (Askunze, 2013). 


\section{LA ECONOMÍA DEL BIEN COMÚN Y LA ECONOMÍA SOCIAL Y SOLIDARIA, ¿SON TEORÍAS COMPLEMENTARIAS?}

Este proceso implica, por lo tanto, la combinación de políticas públicas adecuadas a las necesidades y potencialidades locales junto con la participación activa y solidaria de la sociedad en la autogestión de su desarrollo. Esto exige cambios en las estructuras, es necesario el reconocimiento legal de que hay otras alternativas económicas dentro del propio sistema hegemónico que ayude a la construcción de un proyecto de sociedad, y a su vez, esto implica trascender la democracia puramente representativa en una democracia más directa y participativa, donde la autogestión e incluso los procesos de administración de los políticos deberían ser públicos en su integridad (Defourny, Develtere y Fonteneau, 1999).

\subsection{La economia social y solidaria: ¿modelo alternativo al modelo capitalista?}

La capacidad de la ESS como alternativa al modelo capitalista es una debate abierto (Strada Rodríguez, 2012). Para Gaiger (2007), la ESS constituye una parte diferenciada pero subordinada al modo de producción capitalista, y su mayor logro es poder reproducirse a sí misma, pero no alcanzará a realizar una transformación social, a no ser que se produzcan deficiencias estructurales críticas en la economía.

Por el contrario, para otros autores (Coraggio; 2009; Singer, 2009) el motor de cambio es la voluntad política y el deseo de otra política pues las deficiencias estructurales se han hecho evidente con la crisis económica. Corragio (2007) enfatiza que sería necesario una "acumulación originaria" tal como la tuvo el capitalismo en los países desarrollados, a través de la apropiación o reapropiación de recursos hoy controlados por el capital, aunque con una diferencia: afirmando su valor de uso, y no valor de cambio, dentro de una racionalidad reproductiva. Singer, Gaiger y Nuñez acuerdan en que efectivamente es necesario tener una "estrategia empresarial de mercado y una matriz de acumulación que permitirá crecer y competir exitosamente con el sistema capitalista" (Coraggio, 2007: 30). Se plantea la necesidad de la construcción de sistemas locales, ya sean comunidades históricas o libremente asociadas, relativamente autárquicos y de actividades de producción articuladas y de reproducción de la vida de todos.

En la práctica, Coraggio (2012) señala que a partir de la coexistencia del sector de la ESS con las lógicas y organizaciones del capital y del Estado, se presentarían tres opciones. La primera es "integracionista" y supone que el papel de las nuevas formas económicas sería llenar el vacío que deja el mercado capitalista global, integrando a los trabajadores excedentes y sosteniéndose sobre la base de sus propios resultados. La segunda, de "coexistencia" propiamente dicha, cuestiona el concepto de eficiencia y sostenibilidad por ser parte del sistema empresarial capitalista, y propone un sector desconectado del sistema capitalista, con una lógica propia. La tercera, de "superación" del sistema cultural capitalista, que se daría "sobreconformando las relaciones de competencia entre intereses particulares con relaciones de solidaridad y reciprocidad y el predominio de un bien común legítimamente establecido" (Coraggio, 2005: 5). 
La capacidad transformadora de la ESS puede ser facilitada o no desde las instancias públicas, y por otra parte, pueden ser coaptada por el propio Sector Público como mecanismo de generación de empleo y de inclusión social, más que como alternativa al sistema económico actual (Castelao Caruana, 2009:43). Esta es, sin duda, otra cuestión por dilucidar. En la "Otra Economía" (Coraggio, 2005), el asociacionismo, la participación la creación de capital social, son dispositivos para modificar el sistema, pero en opinión de Vázquez (2000:257): “...las nuevas de ESS y sus intervenciones aparecen ligadas a concepciones usuales de política social, tanto por los destinatarios (poblaciones vulnerables), su organización y por la ubicación institucional", de forma que éstas se configuran como nuevas formas de hacer política social, pero no trascienden a hacer nuevas políticas en un sentido amplio.

En este momento, la ESS se caracteriza por ser un espacio de experimentación de nuevas formas de gestión y de creación de sociabilidad económica y política, tanto es así que la ESS es más un proceso de otra forma de vivir que un camino a un fin determinado. Estas realidades que surgen desde abajo, son consideradas por Santos y Rodríguez (2007:9) como "reformas revolucionarias", entendidas como acciones dentro del propio sistema pero con una lógica no capitalista, capaces de ser sostenibles, desde la articulación de la sociedad civil, y con capacidad transformadora.

\section{3.- La economía del bien común}

La Economía del Bien Común (Felber, 2012) es una propuesta de modelo económico recogido en el libro del mismo nombre, y fue el resultado del trabajo de reflexión del autor junto a un círculo de empresarios austriacos.

La reflexión inicial de la que parte la EBC es que las relaciones sociales se fundamentan en valores como: la honestidad, la dignidad, la cooperación, la solidaridad, la felicidad, la compasión, el altruismo, la amistad, etc. Sin embargo, la economía capitalista está regida por los principios del egoísmo, la competencia y la maximización del beneficio, que ha demostrado estar muy lejos de conseguir una buena calidad de vida para todos los ciudadanos. Esta contradicción se produce porque el sistema económico actual está diseñado para premiar e incentivar precisamente los comportamientos poco éticos e irresponsables.

La EBC defiende la necesidad de medir el éxito de una empresa y de un país, no en función de los beneficios empresariales o por el PIB, sino en relación a la generación bien común. A pesar de la ambigüedad y amplitud del término, Felber (2012) propone que a éste contribuyen principalmente cinco valores que se encuentran en diversas constituciones estudiadas de los países democráticos, que se concretan en: dignidad, solidaridad, sostenibilidad medioambiental, justicia social y democracia y trans- 


\section{LA ECONOMÍA DEL BIEN COMÚN Y LA ECONOMÍA SOCIAL Y SOLIDARIA, ¿SON TEORÍAS COMPLEMENTARIAS?}

parencia4 4 . A partir de esta definición, la EBC ofrece una propuesta para su medición y una "hoja de ruta", encaminada a construir una economía que premie la generación del bien común.

\subsection{Bien común}

El origen del concepto del bien común se encuentra en la tradición aristotélica-tomista pues el hombre "por naturaleza es un animal político o social" que sólo puede alcanzar su propio bien y su felicidad en comunidad (Aristóteles, 1984). Por tanto el bien común, es el bien que se deriva de estar y vivir en comunidad (Conil Sancho, 2004).

En el siglo XX este concepto se amplia e incluye también todas las condiciones materiales junto a los valores, que tienen carácter universal, que permiten a la persona su perfeccionamiento en la sociedad (Argandoña, 2011 y Hollenbach, 2002). Bajo este mismo enfoque se sitúa el comunitarismo, para el cual, el individuo nace en una determinada sociedad, la cual constituye la base para una valoración social de las concepciones de lo bueno y del bien común. Ahora bien, el bien común es diferente en cada comunidad, surge de las prácticas y costumbres existentes en cada momento y en cada lugar (Sandel, 1982). 5

Frente a la larga tradición del concepto en el ámbito de la filosofía y la política, su análisis económico es muy escaso. Por ello destaca el trabajo de Deneulin y Townsend (2007) que delimita el bien común mediante cuatro características empleadas en economía para delimitar la tipología de bienes.

La primera de ellas es que el bien común tiene su origen en una acción conjunta, por lo que es el resultado de la interacción con otras personas y es imposible obtenerlo individualmente. La segunda, es que las personas que participan en su producción también lo hacen en su consumo, porque ambos procesos son simultáneos. En este sentido, es una diferencia importante respecto a los bienes públicos que pueden ser materialmente producidos por una única persona y disfrutado por otras, como por ejemplo el alumbrado público. La tercera es que el bien común no es rival en el consumo porque su disfrute no afecta a la utilidad de los demás, de hecho, el aumento del consumo implica también aumentar su producción. La cuarta es que una persona es excluida del disfrute bien común en la medida en la que no colabore en su construcción.

De acuerdo con estas características, el bien común se define como el resultado de la interacción humana y de la actividad conjunta en el proceso de producción y consumo simultáneos y por tanto no es el resultado de la mera agregación de las acciones individuales. Por tanto, el bien común sólo

4.- Ver Bernal y Edgar (2011). Recogen un análisis de la importancia de los valores como base de la sostenibilidad del sistema económico, social y ecológico en el que vive el hombre.

5.- Diferentes definiciones de bien común consultar Argandoña (2011), Kymlicka, W. (1995). 
se puede producir estando, participando y disfrutando en comunidad, en relación con otros (Denuelin y Townsend, 2007).

Este marco analítico nos permiten afirmar que la propuesta de Felber recoge cuatro tipos de bien común: la dignidad, la justicia, la cooperación y la democracia. 6 En el caso de la sostenibilidad ecológica se puede considerar un bien público global, desde la caracterización económica (Deneulin y Towsend, 2007), porque como es bien sabido, es no rival, disfrutado por todos, y no se puede excluir de su disfrute a nadie, independientemente de que haya contribuido o no a su generación.

Ahora bien, en la teoría de la EBC no hay una argumentación teórica de porqué esos son los valores que constituyen el bien común y no otros. Felber (2012) lo da por hecho basándose en el marco jurídico de los derechos humanos y las constituciones, y apelando al proceso deliberativo, entre los empresarios, del que surge la propuesta. Además, a veces intercambia el empleo del concepto del bien común por el del bienestar y el de felicidad. En nuestra opinión, esta es una línea argumentativa que excede al objetivo de este trabajo, pero se pueden encontrar fundamentos más sólidos en la obra del premio Nobel Amartya Sen (1999), o las propuestas sobre la felicidad pública, diferente al hedonismo, de Zamagni $(2007,2012)$ y la ESS (Razeto, 2015).

Es importante destacar la diferencia y la relación entre el "bien común" y los bienes comunales7. Esta última categoría corresponde a aquellos bienes cuyo consumo no es excluyente pero si es rival en cuanto a su disfrute, como puede ser un banco de pesca en aguas internacionales. Esta característica puede llevar a la conocida tragedia de los comunes (Hardin, 1968), es decir a su sobreexplotación, teniendo en cuenta que cada uno, siguiendo su propio interés, usa en exceso el bien, perjudicando finalmente a todos. Frente a esta hipótesis, la premio Nobel Elionor Ostrom (1998) demostró que la rivalidad en el consumo puede gestionarse de forma democrática y por ello los bienes comunes pueden ser sostenibles, sin necesidad de control público expreso.

La tesis fundamental de su obra se puede sintetizar en que no existe nadie mejor para gestionar sosteniblemente un «recurso de uso común» que los propios beneficiarios (Ostrom, 2003). Un bien comunal implica que todos los individuos de la comunidad tienen derecho a hacer uso u obtener beneficios de un determinado recurso, en consecuencia, se requiere la gestión de la comunidad que permite su sostenibilidad en el tiempo y su disfrute ordenado. Esta misma autora identificó las condiciones de éxito de la gestión comunitaria: la disposición de los medios e incentivos para hacerlo, la existen-

6.- En nuestra opinión, la definición de bien común de la EBC coincide con la de bien relacional de Nussbaum (1986), pues son aquellas experiencias interpersonales en las que el bien lo constituye la relación misma, no sus resultados, como puede ser la confianza, la reputación, el compromiso civil. Este análisis ha sido completado desde la sociología (Donati, 2007), la política (Uhlaner, 1989) y la economía (Gui, 2005). Precisamente la existencia de los bienes relacionales y su "producción" son la base de la "economía civil" propuesta por Zamagni y Bruni (Calvo, 2013).

7.- $A$ veces se emplea el término "bien común" para referirse a "bienes comunales" y "bienes públicos", pero desde una perspectiva económica cada uno presenta características económicas diferentes. 


\section{LA ECONOMÍA DEL BIEN COMÚN Y LA ECONOMÍA SOCIAL Y SOLIDARIA, ¿SON TEORÍAS COMPLEMENTARIAS?}

cia de mecanismos de comunicación necesarios para su implicación, y un criterio de justicia basado en el reparto equitativo de los costos y beneficios.

En nuestra opinión, la gestión sostenible de los bienes comunales, que son bienes y servicios, se basa en los principios que componen el bien común según la propuesta de la EBC, y por tanto, el proceso de gestión de los bienes comunales es un proceso de generación de bien común, aunque no es el único. 8

\subsection{La hoja de ruta de la EBC}

La Economía del Bien Común propone un sistema económico alternativo basado en la cooperación como herramienta básica para fomentar en el ámbito económico el éxito de las relaciones personales y la sostenibilidad.

La siguiente cuestión que se plantea esta teoría es organizar la economía para que genere bien común, a partir de la actividad empresarial. Es evidente que la empresa necesita cubrir sus costes, por tanto un balance financiero saneado es necesario, pero en la actualidad, si una empresa desea pagar bien a sus trabajadores, a sus proveedores, etc. incurrirá en una serie de costes que pueden hacer peligrar su situación financiera, mientras que una empresa que no lleve a cabo estas buenas prácticas tendrá más posibilidades de mantenerse en el mercado. Ante esta contradicción, la EBC propone un sistema que premie a las empresas que fomenten el bien común, ya que la sociedad se está beneficiando directamente de este comportamiento. De esta forma, los incentivos de las empresas y los de la sociedad siguen los mismos parámetros y no entran en conflicto. El elemento clave de esta propuesta es favorecer específicamente la cooperación como motor del progreso de la sociedad, pues gracias a ella, todos ganan, como sustituto de la competencia (Felber, 2012).

Para llevar a cabo la transformación social, Felber propone una hoja de ruta. En una primera etapa, plantea que las empresas, municipios y organizaciones se comprometan a medir su aporte al bien común. Para ello, se ha desarrollado lo que se conoce como Balance del Bien Común. Esta es una herramienta compuesta por una serie de indicadores que miden aspectos de la empresa/organizaciones ligados a valores tales como: dignidad humana, solidaridad, sostenibilidad ecológica, justicia social, participación democrática y democracia social. Estos criterios se desglosan en relación a todos los grupos de interés con los que las organizaciones y empresas se relacionan: proveedores, financiadores, empleados/propietarios, clientes/productos/servicios/co-empresas, y ámbito social: región, generaciones futuras, personas y naturaleza. En las intersecciones de estos criterios aparecen cuestiones concretas para valorar aspectos como las condiciones laborales, el reparto de la renta y del trabajo, etc. (Felber, 2012). 
La evaluación del impacto social de la EBC es una iniciativa más, dentro del conjunto de diferentes metodologías evaluativas del impacto social empresarial: la responsabilidad social corporativa, GRI, el pacto mundial, ISO 26000, B-corporation, etc. Sin embargo esta metodología se diferencia de los anteriores en dos aspectos. El primero de ellos es que ofrecen un valor numérico, no sólo descriptivo de los resultados obtenidos, lo que facilita su comprensión por el resto de agentes. El segundo, y es el más importante, es que inicialmente surge del acuerdo entre empresas y organizaciones en Austria, pero se trata de un proceso abierto al debate y a la mejora continua, gracias a las aportaciones de las diferentes empresas asociadas, por lo que se puede considerar un proceso evaluativo abierto, democrático y en construcción?

En una segunda etapa, la EBC prevé que las empresas/organizaciones que ya hayan medido su participación al bien común mediante el balance, difundan su puntuación mediante su publicación en los medios de comunicación, en la página web de la EBC y por medio de otros cauces todavía en discusión. Además, las empresas etiquetarán sus productos con un distintivo o color en función de la puntuación obtenida, de esta manera los consumidores podrán apoyar a aquellas empresas u organizaciones que comparten sus mismos valores, y apoyar un modelo productivo concreto en su caso. El consumidor, a través del balance del bien común, tiene la información que necesita y puede ejercer su derecho de participación y su responsabilidad individual y colectiva en las compras que realiza.

En una tercera etapa, la EBC considera que sería necesario fijar por ley medidas que incentiven el bien común de las empresas, organizaciones y municipios, mediante: incentivos fiscales, discriminación positiva en los procesos de contratación pública, cooperación con la investigación universitaria... de forma que la sociedad premie a las empresas que están generando bien común, frente a aquellas que no lo hacen.

En nuestra opinión, la EBC no es una teoría escéptica sobre la naturaleza humana, pues su supuesto de partida es una visión antropológica del hombre social que se preocupa por los demás, por tanto en sus diferentes facetas, incluida la económica, puede actuar movido por sus valores. De hecho, debido a la multidimensionalidad del comportamiento humano es posible, y además real, encontrar muestras de consumidores y empresas con un comportamiento guiados por éstos. Este es punto en común con la ESS y con otras propuestas como la con la teoría de la reciprocidad (Zimagni y Bruni, 2007; Zimagni, 2012), la teoría del valor compartido (Porter y Kramener, 2011), o el capitalismo consciente (Sisodia, 2011).

Sin embargo, la EBC, considera que las instituciones importan en la medida en la que crean incentivos para los comportamientos y puedan generar un contexto más favorable a las empresas y organizaciones no puramente capitalistas. En la situación actual, el sector público ofrece un marco jurídico 


\section{LA ECONOMÍA DEL BIEN COMÚN Y LA ECONOMÍA SOCIAL Y SOLIDARIA, ¿SON TEORÍAS COMPLEMENTARIAS?}

a los mercados capitalistas que protege la maximización de beneficios, con relativas pocas restricciones respecto a otros derechos de los participantes en los procesos económicos.

Las instituciones económicas actuales premian el egoísmo, aunque afecte negativamente al resto de actores sociales, no son "neutrales" en cuanto a favorecer unos determinados comportamientos u otros. De hecho, no existe tal cosa como el "libre mercado", éste está instituido de antemano por los poderes públicos de acuerdo con los intereses de los grupos con poder y capacidad de presión, favoreciendo a unos grupos frente a otros. Posteriormente, la actividad del sector público intenta solucionar los "fallos del mercado": pobreza, desigualdad, deterioro medioambiental,... que ha dado lugar al Estado de Bienestar, cuya sostenibilidad económica está puesta en duda en la actualidad.

De forma alternativa, el sector público, podría diseñar un marco legal del mercado que fomentase la cooperación y los comportamientos éticos y responsables. La EBC, como cualquier sistema económico, necesita de unas "reglas de juego", tal como muestran las propuestas institucionalistas (North, 1990, Esparta Soloeta, 2002). En la EBC no hay más regulación de la que pueda existir hoy en día, pero su objetivo no es "enmendar" los resultados del mercado, sino corregir los mecanismos e incentivos para generar otros resultados desde el propio mercado en consonancia con valores humanos, de forma que el sistema jurídico y social premie la generación del bien común y no la maximización de los beneficios a toda costa.

Consideramos que estos elementos describen la propuesta teórica básica de la EBC sobre el funcionamiento de las organizaciones, el mercado y el sector público. De forma adicional, Felber (2012) sugiere una serie de propuestas para limitar la acumulación del capital, evitar la creación de barreras que imposibiliten el ejercicio real de las libertades y para que la maximización del beneficio no sea el objetivo fundamental de la empresa. Puesto que el capital es un medio, y no un fin, existe una serie de usos permitidos de los beneficios como son: las inversiones con rentabilidad social, las provisiones para pérdidas, la cancelación de deudas, el reparto entre los colaboradores de la empresa y los préstamos a clientes, proveedores o trabajadores sin intereses. Por el contrario estarían prohibidas las siguientes prácticas: el reparto de beneficios entre propietarios que no trabajen en la empresa, la disociación de poder y responsabilidad y la concentración de poder económico (Felber, 2012).

Asimismo, sólo las personas que trabajan en la empresa pueden participar en los beneficios que ésta genera, además se establece un salario mínimo y máximo, como incentivo al esfuerzo y la responsabilidad, y como límite a la acumulación de riqueza, unido a una dote democrática que recibirían todas las personas en el comienzo de su vida laboral como medio para favorecer la igualdad real de oportunidades. ${ }^{10}$ 
En este nuevo marco jurídico, es posible la competencia entre las empresas, así como la quiebra, pero no incentiva la lucha para que las demás desaparezcan por dos motivos. El primero es que esa lucha no se traduce en un aumento de beneficios, llegado a unos límites establecido. El segundo es que la empresa que más colabore con las demás, tendrá mejor balance del bien común, y mayor reducción de costes, por lo que tiene mayores probabilidades de continuidad con esa estrategia que con la de la competencia.

De esta forma la EBC presenta un modelo económico basado en la iniciativa empresarial, pero no competitiva, sino en la cooperación, donde el beneficio no consiste en la acumulación de riqueza, sino en la creación de renta y una vida digna para todos, de acuerdo con criterios éticos y de sostenibilidad.

La EBC, también propone un proceso de construcción democrático y asambleario, que puede iniciarse desde el ámbito local mediante diferentes vías. El ayuntamiento, como organización, puede realizar su propio balance, de forma que sea consciente de cómo está contribuyendo a la generación del bien común en su comunidad. De hecho esta es una de las estrategias seguidas en España, pues partiendo de la participación de diferentes colectivos que han expuesto y compartido buenas prácticas se ha creado una matriz del bien común municipal, pero a diferencia de la matriz empresarial, no tiene valores numéricos ${ }^{11}$.

Una segunda vía es que un municipio del bien común invita al empresariado del lugar a realizar el balance del bien común. La tercera es el desarrollo participativo de un "índice del bien común municipal" entre la ciudadanía, con el objeto de que la comunidad identifique cuáles son las cuestiones que verdaderamente configuran el bien común en su municipio. Esta sería la vía de inicio que facilitaría en el futuro la participación ciudadana para promover una "convención económica municipal" y fijar unas reglas jurídicas que deben regir la economía, en parte a nivel municipal, para llegar finalmente a nivel regional, nacional y a nivel europeo, y en futuro unirse en una "región del bien común".

\subsection{Modelo político y social de la EBC}

La EBC aboga por un cambio social y político, sin los que es imposible construir otra economía, sin embargo estos proyectos no están definidos con la profundidad y detalle como la hoja de ruta de cambio económico.

En el plano social, la Economía del Bien Común defiende la necesidad de una educación en los valores de la educación y no de la competitividad. Por ello, es necesario una educación para el medioambiente, para la democracia, para los sentimientos, la empatía y la cooperación, etc. Además, en 


\section{LA ECONOMÍA DEL BIEN COMÚN Y LA ECONOMÍA SOCIAL Y SOLIDARIA, ¿SON TEORÍAS COMPLEMENTARIAS?}

la medida en las que las empresas sean un medio para el bien común, y no un fin en sí mismas, son el marco adecuado para que la persona encuentre su desarrollo personal por medio del trabajo, ya sea en la empresa o por otras vías de no mercado. Se suma una reivindicación de la creación de espacios ciudadanos, mediante reformas jurídicas que permitan la gestión de bienes comunales y empresas ciudadanas, que habiliten el ejercicio de una ciudadanía plena, en deberes, pero también en derechos, como expresión de la sociedad civil (Felber, 2012, capítulo 5).

En el plano político, se aboga por una implantación de separación de poderes, y propone para ello, una serie de pasos concretos hacia una democracia tridimensional que albergaría: una democracia indirecta o representativa, una directa y una participativa (Felber, 2012:161). La democracia representativa debería completarse con mecanismos de participación, como por ejemplo, los presupuestos participativos, y con diferentes mecanismos que permitieran el ejercicio de la democracia directa, como verdadera muestra de la soberanía del pueblo. Ello supone crear en las constituciones las estructuras y cauces necesarios para dar voz al pueblo -y no sólo voto- en las decisiones políticas, de manera que éste pueda bloquear propuestas legislativas del gobierno que no tienen el apoyo popular, sacar del gobierno a un partido elegido que no cumple con su programa político y proponer iniciativas legislativas populares vinculantes.

\section{4.- ¿Hay complementariedad entre estas propuestas?}

\subsection{Elementos comunes}

La EES cuenta con aportaciones desde los años 70 desde el ámbito práctico, que lleva parejo un desarrollo teórico muy amplio. Por su parte, la EBC inicia su trayectoria en 2010 con una propuesta teórica muy concreta, basada en reflexiones sobre la realidad actual, pero sin contar con experiencias expresas de Economía del Bien Común.

A pesar de ello, consideramos que ambas corrientes tienen una serie de elementos comunes como son: una visión antropológica basada en el hombre como ser social y la importancia de los valores, la aspiración para construir un modelo económico alternativo fundamentado en la democracia como metodología de construcción y la sociedad civil, el activismo social y político y el cambio de modelo desde lo local.

Frente a la antropología subyacente de la economía de mercado capitalista que reduce las motivaciones del ser humano al homo economicus, la EES y la EBC reivindican un paradigma de hombre social, apelando a la existencia de la multidimensionalidad de las motivaciones. Asimismo, 
comparten el supuesto de la existencia de valores en la naturaleza humana, que se extiende a todas las relaciones sociales. El marco epistemológico de esta afirmación reside en el análisis teórico y empírico de Polanyi, el cuál afirma que "el gran descubrimiento de la reciente investigación histórica y antropológica es que la economía humana está sumergida por regla general en las relaciones sociales de los hombres" (Polanyi, 2007:94), y por ello "el sistema económico es una mera función de la organización social" (Polanyi, 2007:98). Este marco es el empleado por autores como Laville o Corragio pertenecientes a la ESS, pero la EBC carece de una fundamentación teórica de este calado.

La economía, por tanto, no puede tener otro fin que estar servicio de las personas y por ello ambas propuestas aspiran a construir un modelo económico alternativo. El camino propuesto por la ESS para la sostenibilidad del sistema es la vía de la democratización, elemento que la EBC también incorpora en su modelo. Ello supone la reivindicación de la democracia directa, los procesos de cambio desde abajo y desde lo local, la redefinición del papel del sector público como creador de espacios para la autogestión de la sociedad civil y la reivindicación de la democratización de la economía.

La vía democrática de transformación social implica que en cada momento del proceso haya que optar a favor de quiénes y de qué políticas estamos, y desde dónde, quiénes gobiernan y para qué. Esta debería ser siempre una opción consciente del pueblo, individual y colectiva; y para que así ocurra, debe ser construida, día a día, desde abajo (Villasante, 1995). Para ello ambas teorías proponen la realización de asambleas constituyentes, ya que todos los pueblos deberían poder ejercer su derecho a expresar sus puntos de vista e intereses en un proceso permanente (Felber, 2012).

Lo que aparece en la ESS y la EBC es una nueva cultura de poder basada tanto en la participación colectiva creciente en el proceso de toma de decisiones como en la ejecución de las resoluciones y el control de los resultados y la gestión gubernamental toda, y para ello es necesario el empoderamiento creciente de los individuos y de los pueblos. Se refuerza así también la importancia y la reivindicación de la gestión de los bienes comunes, que pueden ser gobernados a través de la acción colectiva voluntaria, tal como comentábamos con anterioridad. La definición de los derechos individuales, entre ellos el de propiedad privada, cuenta con un largo recorrido, especialmente, en la cultura occidental, pero el ejercicio de la vida en común requiere nuevas fórmulas de derecho sobre los bienes comunales (Bollier y Helfrich, 2014). Asimismo, el derecho de propiedad individual debe estar sujeto a límites, en función de los procesos democráticos deliberativos (Felber, 2012 y Razeto, 2015).

La vocación de transformación del modelo económico imperante trasciende el debate teórico y se traduce en activismo social y político. Ambas cuentan con grupos locales articulado en redes nacionales e internacionales como estrategia para la puesta en práctica de otra economía y para la transformación social. ${ }^{12}$ 


\section{LA ECONOMÍA DEL BIEN COMÚN Y LA ECONOMÍA SOCIAL Y SOLIDARIA, ¿SON TEORÍAS COMPLEMENTARIAS?}

Ello supone un cambio en la forma de hacer política, donde el detonante natural esperado, tanto en la EBC y la ESS, es la demanda de la sociedad civil de una democracia desde abajo, de otra forma de hacer política y economía. Esto es más factible de llevar a cabo en el ámbito de local, donde la democracia participativa es más fácil de ejercitar por las personas, aspecto especialmente relevante para la ESS.

Esto supone, un cambio en los objetivos del desarrollo local desde la competitividad a la generación de bien común y la cooperación, por lo que todos los agentes deben compartir ese objetivo, mediante un cambio de valores y de incentivos. Por su parte, las administraciones locales, a pesar de tener competencias limitadas, conocen mejor la realidad del territorio donde se encuentran que otras administraciones superiores y su involucración es indispensable para empoderar a los individuos y posibilitar la creación de proyectos de ESS y EBC.

\subsection{Elementos diferenciales}

Los elementos diferenciadores que presentan ambos modelos residen en la visión de cómo la democracia se incardina en la empresa y el papel del capital, la determinación del valor social, las relaciones económicas en el mercado, la amplitud de las actividades mercantilistas y el papel del sector público.

\subsubsection{La empresa y el capital}

La ESS aparece como una respuesta a problemas sociales acuciantes, como el desempleo, la pobreza, la necesidad de servicios, etc. y de ahí la originalidad de sus respuestas a nivel microeconómico. Mientras que la EBC surge ante la convicción de que es necesario superar el modelo económico neoliberal destructivo actual mediante otro acorde con los valores humanos, las necesidades sociales y medioambientales. Tiene la voluntad de ir cambiando el sistema económico al cambiar y reorientar la actividad empresarial, pero parte de las organizaciones empresariales tanto clásicas como de la Economía Social y no propone ningún tipo de organización nueva, sino la transformación de la actividad empresarial para crear valor compartido y sostenibilidad.

La red de la ESS no admite formas empresariales donde prime el capital, y existe además la necesidad de cumplir unos requisitos mínimos, acordes con los valores y principios de la ESS. La EBC abre la puerta a proyectos cuyo compromiso social puede ser inicialmente reducido y bajo cualquier forma societaria donde puede primar el capital, y sin tener un comportamiento mínimamente democrático, pero sí intención de iniciar un proceso de aprendizaje, reorientación y transformación de la actividad empresarial a través de la aplicación del Balance del Bien Común.

Este elemento es, sin duda un elemento de divergencia importante, pues en el caso de la ESS existe una frontera clara entre las empresas que pertenecen a su proyecto y las que no, y por tanto 
hay una parte del tejido empresarial actual, la gran mayoría, que no tiene cabida en la ESS. Por el contrario, la EBC abre la posibilidad de llegar a un público al que le puede resultar más difícil asumir todos y cada uno los principios de la ESS.

Así, la EBC acepta que una empresa sin un trato justo en el reparto de los beneficios, donde prime el capital, y sin democracia obtenga una puntuación de 700 puntos respecto a 1.000 , frente a la ESS, que no admitiría nunca este tipo de empresa. Ahora bien, si tenemos en cuenta la visión completa del modelo de la EBC, la empresa "ideal" de la EBC, la que genera más bien común, es aquella que cumple con los principios de la ESS, que sería la que obtendría la puntuación máxima.

Un elemento fundamental de la EBC son una serie de propuestas para limitar la acumulación, uso y retribución del capital, por tanto coincide con la ESS sobre el papel subordinado del capital. Estas medidas están encuadradas dentro de una lógica teórica que pretende que el beneficio sea el medio y no el fin, pero sólo se podrían aplicar si fuesen aprobadas por los cauces democráticos pertinentes (Felber, 2012).

\subsubsection{La contabilidad del valor social}

La forma de comprobación del valor social a nivel microeconómico también es diferente en cuanto a la metodología. En el caso de la ESS, existe un comité de voluntarios que realizan la evaluación mediante el balance social, y en la EBC está planteado como un sistema bidireccional entre la empresa interesada y los auditores de la asociación de la Economía del Bien Común ${ }^{13}$. Este es un aspecto fundamental que debe ser evaluado y tratado en la EBC para evitar que se convierta en un sello más, 0 en un tipo de responsabilidad social avanzada. El aspecto de la medición del impacto social, mediante el balance del bien común, aunque con sus carencias metodológicas, ha sido un acierto porque presenta una forma de comunicación rápida y concreta de la propuesta hacia el resto de la sociedad. Además es una herramienta de aprendizaje porque permite a la empresa saber en qué estadio se encuentra, qué aspectos puede mejorar y cuál es la ruta a seguir. De hecho, el mercado social de REAS (Red de Economía Alternativa y Solidaria) en España ha incorporado un formato similar al propuesto por la EBC para la medición cuantitativa y el etiquetado para la evaluación de las organizaciones solidarias con una doble finalidad: para el proceso de mejora de la organización, y para transmitir información al resto de la sociedad. ${ }^{14}$

En el orden macroeconómico, la EBC es consciente de la necesidad de medir los logros sociales con otros parámetros diferentes al PIB, y por ello propone la necesidad de una métrica del Producto del Bien Común Bruto, aunque esta propuesta todavía no se ha desarrollado, aspecto que la ESS no contempla. 


\section{LA ECONOMÍA DEL BIEN COMÚN Y LA ECONOMÍA SOCIAL Y SOLIDARIA, ¿SON TEORÍAS COMPLEMENTARIAS?}

\subsubsection{Las relaciones económicas de producción, distribución y consumo}

La ESS es una corriente transformadora, pues plantea que las maneras de organizarse económicamente son múltiples y variadas, no presenta un único camino o ruta para el proceso de transformación, por el contrario, dicho proceso de creación surge de la experimentación, de la práctica y del saber compartido. La realidad construida y compartida con bases solidarias sirve a otros colectivos para iniciar nuevos procesos, aportando nuevos saberes, como por ejemplo es el caso de las monedas sociales, las finanzas solidarias, los mercados sociales, el comercio justo, etc. Esta es la forma en la que la solidaridad se incorpora a los procesos económicos. Pero va un paso más allá, y además de empoderar a los sujetos haciéndoles recuperar su dimensión política gracias a la auto-gestión económica a nivel local, reivindica el derecho a decidir qué tipo de desarrollo desean vivir, sin una imposición externa a través del Estado o de políticas comerciales con terceros países.

Por su parte, la EBC tiene como objetivo central que las decisiones económicas sigan basándose en los precios, pero que estos reflejen los costes y los beneficios sociales derivados de las relaciones económicas. El marco de incentivos institucionales es indispensable para generar un modelo económico distinto, y al igual que el actual sistema premia la acumulación de riquezas sin tener en cuenta ningún efecto sobre las demás personas, la EBC pretende revertir ese modelo. Por ello se hace imprescindible que la definición de los costes y beneficios sociales se articulen bajo un principio general de identificación del bien común, y bajo procesos democráticos que legitimen lo que las comunidades entienden por bien común. Al aplicar la matriz, se alinea la actividad empresarial con los fines y necesidades sociales, en lugar de convertirlos en externalidades que contribuyen a reforzar la contraposición entre los intereses empresariales y sociales, de modo que ambos se aúnan y contribuyen a que el progreso económico y el progreso social vayan de la mano.

Sin embargo, la EBC no tiene un marco teórico de cómo fomentar la creación de redes cooperación, si no es por medio de incentivos públicos. En este sentido, la ESS ofrece aprendizajes sobre los procesos de cooperación entre las personas, pues a pesar de la falta de incentivos monetarios, posee un gran bagaje de buenas prácticas sociales, económicas, democráticas....de las que la EBC puede y debe beneficiarse, al igual que existen muchas otras corrientes con las que puede entrar en diálogo, economía de los cuidados, decrecimiento, etc. y viceversa.

Desde nuestra perspectiva, ambas propuestas no son contradictorias, por el contrario, están buscando soluciones complementarias y necesarias para cambiar el funcionamiento del mercado capitalista. Si no existe una conciencia ciudadana, solidaria y ética, es muy difícil que se produzca una transformación institucional, como propone la EBC. Por otro lado, la reforma de mercado propuesta para la EBC consideramos que es un marco institucional adecuado para el desarrollo de las iniciativas de ESS, y su ampliación en ámbito económico. 


\subsubsection{Sector público}

El rediseño del papel del sector público en ambas corrientes es fundamental. Ya nos es solucionador de los "fallos del mercado", si no el co-creador de otro tipo de mercado, basado en permitir a la sociedad civil ser la artífice y protagonista de la vida pública. Los cambios que ambas corrientes proponen es el fortalecimiento de la democracia directa, espacios para la autogestión y la redefinición de los derechos de propiedad, el diseño de políticas de desarrollo, aspectos ya tratados, la modificación de los incentivos del mercado y los parámetros de valoración del propio funcionamiento del sector público.

Ambas corrientes coinciden en crear incentivos desde el sector público para las actividades con impacto social mediante las cláusulas sociales, pero la ESS sólo propone la aplicación de cláusulas sociales para sus organizaciones. La EBC, por su parte, amplia esta propuesta para transformar todo el mercado como un sistema institucional que fomente y reconduzca el comportamiento de los actores económicos, y los alinee con los valores humanos básicos en sus decisiones económicas.

La EBC confía en que los procesos democráticos sean lo suficientemente fuertes e importantes para que la sociedad civil controle como el sector público puede incidir en todo el diseño del mercado. Sin embargo, la ESS considera que esta es una labor que se debe realizar principalmente a escala local, porque es la escala de dimensión humana dónde se pueden generar relaciones de confianza, y el diseño de precios se puede realizar de forma autogestionada (Carragio, 2009).

Por último, la EBC va un paso más allá respecto a las administraciones y propone que ellas mismas sean generadoras de bien común a través de su gestión interna, en su relación con los proveedores, y con los ciudadanos, y como ejemplo del cambio de valores y objetivos, y en esta reconducción gracias a la aplicación del BBC a los municipios, que como hemos comentado antes, se puede aplicar a todo tipo de organización: empresas, ONG's, comunidades de vecinos, etc.

\section{5.- Conclusiones}

En este trabajo se han presentado los elementos básicos de la ESS y de la EBC, con el objeto de determinar hasta qué punto se pueden considerar propuestas complementarias. Nuestra primera valoración es la existencia de una serie de elementos comunes como es la reivindicación de la necesidad de otro modelo económico, la defensa de la existencia de unos valores humanos en las relaciones económicas y la democracia como elemento fundamental de transformación social. 


\section{LA ECONOMÍA DEL BIEN COMÚN Y LA ECONOMÍA SOCIAL Y SOLIDARIA, ¿SON TEORÍAS COMPLEMENTARIAS?}

En ambas, la sociedad civil no se representa como un "contrapoder" sino como la fuente de un proceso integral de gestación de nuevos valores y relaciones. La superación del capitalismo requiere otra lógica del funcionamiento diferente a la de la acumulación del capital, y esto significa una transformación de las conciencias. Esta se inicia cuando los pueblos tratan de dar respuesta a sus necesidades y se organizan proponiendo alternativas, impulsando la participación democrática y organizándose políticamente, construyendo así un poder político-cultural desde abajo. Se trata de un proceso integral de cambio consciente y activo, que gesta una nueva realidad que abarca a todas las áreas de la vida, pues todas ellas están interrelacionadas (Rauber, I. 2006).

Lo que aparece en la ESS y la EBC es una nueva cultura de poder basada en la participación colectiva democrática en el proceso de toma de decisiones, en la ejecución de las resoluciones y el control de los resultados y la gestión gubernamental, y para ello es necesario el empoderamiento creciente de los individuos y de los pueblos. Aparece así también la importancia de la gestión de los bienes comunes, que pueden ser gobernados a través de la acción colectiva voluntaria, tal como sugiere los estudios de Ostrom (2003), como esfera diferente al mercado y al estado.

Frente al sometimiento a "la lógica de los mercados" se aboga, desde la ESS y la EBC, por una supeditación del mercado a la racionalidad político democrática, es decir, como única manera de reequilibrar las relaciones de poder y hacer que el sistema funcione al servicio de la sociedad, y no al revés. De esta manera, sería posible recuperar el sentido original de la Ciencia Económica, definida como la ciencia que se encarga de la creación de riqueza, su distribución y consumo con el objetivo de cubrir las necesidades humanas y aumentar su bienestar (Felber, 2012).

Sin embargo, ambas corrientes ofrecen una visión diferente de cómo podría producirse un cambio en el sistema económico mediante la democracia, que nos conduzca a una vida sostenible. Este es sin duda el punto de tensión o divergencia pues dicho proceso de democratización en la ESS se concreta en la autogestión de una gran parte de la actividad económica a escala local. La EBC por su parte, propone crear mecanismos e incentivos que generen otros resultados desde el mismo mercado y promuevan un contexto más favorable a las organizaciones que tienen un compromiso con la sociedad, reorientando todos los procesos económicos actuales hacia el bien común.

La implementación práctica de estas propuestas teóricas pueden presentar el mismo riesgo, no tener la capacidad transformadora suficiente. En el caso de ESS, se puede deber, en nuestra opinión, por no llegar a todos los sectores de la sociedad debido a un discurso que plantea un modelo con unos parámetros muy diferentes a los actuales. Por su parte, la EBC necesita de los medios institucionales que permitan a la sociedad civil ejercer una democracia que controle realmente al sector público. De lo contrario, la aplicación de los incentivos públicos para modificar los precios no contará con la suficiente garantía de que realmente reflejen los beneficios y costes sociales. 
Una ventaja de la EBC es que construye un nuevo marco analítico, pues permite el empleo de otro lenguaje y otra dialéctica, pero dentro de la lógica de mercado. Además, la vía de transformación propuesta por la EBC puede incorporar a más agentes económicos y políticos que la ESS, pues es un proceso gradual, frente a la ESS que es más exigente, en cuanto a la necesidad de adhesión a todos sus principios. Pero no debemos olvidar que, bajo los parámetros de la EBC, los proyectos que generarían más bien común son los que están desarrollados en la ESS.

A partir del reconocimiento en las diferencias en la metodología del cambio, consideramos que existen varios ámbitos de complementariedad teórica y práctica. Desde una perspectiva teórica, la EBC tiene menor fundamentación, por lo que podría nutrirse de elementos más elaborados procedentes de la ESS, como la visión antropológica, los procesos democráticos, la creación de redes de cooperación como los mercados sociales, etc. Asimismo, la propuesta de investigar las posibilidades de medición en una economía del producto del bien común es innovadora, y sugiere la necesidad de profundizar su relación con otras visiones del progreso de una sociedad, como es la economía de la felicidad, el buenvivir, la teoría de las capacidades, etc., que tienen en cuenta otras dimensiones del bienestar de la persona, y que podrían ofrecer a la economía solidaria nuevas herramientas de evaluación. Las mediciones son herramientas importantes para las actividades de difusión de los criterios normativos y para poder formular y evaluar políticas públicas más efectivas, puesto que: "Lo que medimos afecta a lo que hacemos; y si nuestras mediciones son defectuosas, nuestras decisiones se pueden distorsionar" (Stiglitz, Sen y Fitoussi, 2013:1).

Por otra parte, desde una perspectiva práctica, el recorrido de la ESS es mucho más amplio y variado, que aporta a la EBC todo un campo de buenas experiencias y proyectos reales como referencia y ambas, a su vez, se pueden nutrir de planteamientos y soluciones que surgen en la gestión de los comunes, la economía colaborativa, la economía circular, etc.

La interacción permitiría avanzar en algunas grandes líneas como son: democratizar la economía de mercado internacional, sostener la economía de mercado territorial, relegitimar la economía no mercantil y tomar en consideración la economía no monetaria, lo que implica la creación de nuevos espacios públicos a nivel regional e internacional.

Sin duda alguna, el gran desafío de ambas propuestas es llegar a demostrar que los principios democráticos pueden ser un modo de gestión, de mediación, y de regulación económica en la producción y el consumo de bienes y servicios (Fraisse, L. 2004:2). Por tanto, existe todo un campo de confluencia teórica y práctica en el que trabajar con otras corrientes en aras de comprender y mejorar los procesos democráticos, la participación activa y solidaria de la sociedad en la autogestión de su desarrollo, los cambios institucionales del mercado y del sector público: jurídicos, políticos y económicos, una nueva métrica del valor social y su incorporación a los procesos económicos. 


\section{Bibliografía}

ACOSTA, A. \& MARTÍNEZ, E. (Comps.) (2011): La naturaleza con derechos: de la filosofía a la política, Abya-Yala, Quito.

ALVES DA SILVA, R.M. (2006): Entre o combate à seca e a convivência com o semiárido. Tesis doctoral. Brasilia, Universidad de Brasilia, en: http://repositorio.unb.br/bitstream/10482/2309/1/2006_Roberto\%20Marinho\%20Alves\%20da\%20Silva.pdf

ARGANDOÑA, A. (2011): "El bien común", Documento de Investigación DI-937, IESE Business SchoolCátedra "la Caixa" de Responsabilidad Social de la Empresa y Gobierno Corporativo.

ARISTÓTELES (1984): Nicomachean Ethics. En: Barnes, J. (ed.), The complete Works of Aristotle, vol. 2. Pricenton: Princenton University Press.

ARRUDA, M. (2004): “¿Qué es la Economía Solidaria? El renacimiento de una sociedad humana matrística", Ecología Política, 27, 71-76.

ASKUNZE, C. (2013): "Más allá del capitalismo: alternativas desde la Economía Solidaria", Documentación Social, 168, 97-116.

ASOCIACIÓN DE ECONOMÍA DEL BIEN COMÚN (2014): Balance del Bien Común, Asociación de Economía del Bien Común en http://economia-del-bien-comun.org/es/content/primeros-pasos

ASOCIACIÓN DE ECONOMÍA DEL BIEN COMÚN (2014): Balance del Bien Común Municipal, Asociación de Economía del Bien Común en http://www.ebczaragoza.org/documentos/

BERNAL, E. \& EDGAR, C. (2011): "Human consciousness as a base for sustainability in socio-economic-ecological systems", International Journal of Environment and Sustainable Development, 10 (3), 229-245.

BOCAYUVA, P.C.C. (2000): "A economia solidária entre a resistência e a utopia", Proposta, 86, 18-29.

BOLLIER, D. \& HELFRICH, S. (Ed.) (2014): The wealth of the commons: A world beyond market and state, Levellers Press.

BORZAGA, C. \& DEFOURNY, J. (2004): The emergence of social enterprise, Psychology Press.

CALVO, P. (2013): "Fundamentos de la economía civil para el diseño de las Organizaciones", Revista Internacional de Organizaciones, 10, 65-84.

CARRASCO, C. (2011): "La economía del cuidado: planteamiento actual y desafíos pendientes", Revista de Economía Crítica, 11, 17-32. 
CASTELAO CARUANA, M.E. (2009): "La Economía Social y Solidaria en las políticas públicas argentinas, instrumento de política o alternativa socioeconómica. Un análisis preliminar", Revista Venezolana de Economía Social, Año 9, nº 17, Enero-Junio, 30-48.

CHAVES, R. \& DEMOUSTIER, D. (Dir.) (2013): The emergence of social economy in public policy. An international perspective, Bruxelles: Peterlang publishers.

COMITÉ ECONOMICO Y SOCIAL EUROPEO (2015): "Dictamen del Comité Económico y Social Europeo sobre el tema La Economía del Bien Común: un modelo económico sostenible orientado a la cohesión social". En https://dm.eesc.europa.eu/eescdocumentsearch/Pages/opinionssearch.aspx

CORAGGIO, J.L. (2005): "Economía social como vía para otro desarrollo social", Boletín Tecnología para la Organización Pública, vol. 12.

CORAGGIO, J.L. (2007): "Una perspectiva alternativa para la economía social: de la economía popular a la economía del trabajo". En: Coraggio, J.L., La Economía Social desde la periferia. Contribuciones latinoamericanas, Buenos Aires: Altamira, 165-194.

CORAGGIO, J.L. (Ed.) (2009): ¿Qué es lo económico? Materiales para un debate necesario contra el fatalismo, Buenos Aires: Ciccus.

CORAGGIO, J.L. (2011): Economía social y solidaria. El trabajo antes que el capital, Quito: Abya Yala.

CORAGGIO, J.L. (2012): "Las tres corrientes vigentes de pensamiento y acción dentro del campo de la Economía Social y Solidaria (ESS): Sus diferentes alcances". Acceso virtual: 20 de junio 2016.

CRESPO, B. \& SABIN, F. (2014): "Los mercados sociales. La economía solidaria en acción transformadora", Documentación Social, 174, 95-116

DASH, A. (2013): "Towards and Epistemological Foundation for Social and Solidarity Economy". UNRISD Conference on the Potential and Limits of Social and Solidarity Economy, Geneva.

DE AQUINO, T. (1981): Summa Theologica, New York, Christian Classics.

DEFOURNY, J. \& NYSSENS, M. (2012): "El enfoque EMES de la empresa social desde una perspectiva comparada", CIRIEC-España, Revista de Economía Pública, Social y Cooperativa, 75, 7-34.

DEFOURNY, J., DEVELTERE, P. \& FONTENEAU, B. (1999): Social Economy - North and South, HIVA, UKLeuven.

DENEULIN, S. \& TOWNSEND, N. (2007): "Public goods, global public goods and the common good", International Journal of Social Economics, 34 (2), 9-36.

DI MAGGIO, P.J. \& POWELL, W. (1983): "The Iron Cage Revisited: Institutional Isomorphism and Collective Rationality in Organizational Fields", American Sociological Review, 48 (2), 147-160.

DONATI, P. (2007): "Capitale sociale, reti associazionali e beni relazionali”, Impresa Sociale, 2 (76), 168-191. 


\section{LA ECONOMÍA DEL BIEN COMÚN Y LA ECONOMÍA SOCIAL Y SOLIDARIA, ¿SON TEORÍAS COMPLEMENTARIAS?}

ESPARTA SOLOETA, I. (2002): Análisis Económico Institucionalista: Una economía política para la transformación social, Escuela Universitaria de Estudios Empresariales de Bilbao, UPV/EHU, disponible en:

http://pendientedemigracion.ucm.es/info/ec/jec8/Datos/documentos/comunicaciones/Fundament os/Esparta\%20l\%F1aki.PDF

ETXEZARRETA, E. \& MONRANDEIRA, J. (2012): "Consideraciones conceptuales sobre la Economía Social a la luz de la Ley 5/2011", Revista vasca de economía social / Gizarte ekonomiaren euskal aldizkaria, 8, 7-36.

EVERS, A. \& LAVILLE, J.L. (Ed.) (2004): The third sector in Europe, Edward Elgar Publishing.

FAJARDO GARCIA, G. (2012): "El concepto legal de economía social y la empresa social", Revista vasca de economía social, 8, 63-84.

FAVREAU, L., LACHAPELLE R. \& LAROSE G. (2003): "Social and solidarity economy: A credible alternative on a global scale?", Economie et solidarités, 190-196.

FAVREAU, L. \& VAILLANCOURT, Y. (2001): "Le modè le québécois d économie sociale et solidaire", Revue internationale de I économie sociale, 281, 45-67.

FELBER, C. (2008): Neue Werte Für die Wirtschaft. Eine Alternative zu Kommunismus und Kapitalismus, Ed. Deuticke, Viena.

FELBER, C. (2012): La Economía del Bien Común, Grupo Planeta, Ediciones Deusto, Barcelona.

FRAISSE, L. (2004): "Economía solidaria y democratización de la economía". En: J.L. Laville (ed.), Economía social y solidaria. Una visión europea, Buenos Aires, Fundación OSDE -Universidad Nacional de General Sarmiento- Editorial Altamira.

GAIGER, L.I. (2007): "La Economía Solidaria y el capitalismo en la perspectiva de las transiciones históricas". En: Coraggio, J.L. La economía social desde la periferia, contribuciones latinoamericanas, Ed. Altamira-UNGS, Buenos Aires.

GALLICCHIO, E. (2004): "El desarrollo económico local en América Latina. ¿Estrategia económica o de construcción de capital social?". En: Seminario gobierno local y desarrollo, 28 y 29 de Enero, Barcelona, Centro Latinoamericano de Economía Humana.

GARAFOLI, G. (1992): "Endogenous development and Southern Europe: An introduction". In: Garafoli, G. (Ed.), Endogenous development and Southern Europe, Avebury; Brookfield, Vt., USA: Ashgate Pub. Co, Aldershot, Hants., England.

GEORGESCU-ROEGEN, N. (1971): The entropy law and the economic process, Cambridge, Mass. and Londres, Harvard University Press.

GÓMEZ CALVO, V. \& GÓMEZ-ÁLVAREZ, R. (2014): "Herramientas de la Economía del Bien Común para la transformación económica, social y política", Revista Deusto de Estudios Cooperativos, 5, 13-42. 
GUERRA, P. (2010): "La Economía Solidaria en Latinoamérica", Papeles de relaciones ecosociales y cambio global, 110, 67-76.

GUERRA, P. (2011): "¿Cómo denominar a las experiencias económicas solidarias basadas en el trabajo? Diálogo entre académicos latinoamericanos acerca de la polémica conceptual", Otra Economía, 1(1), 21-27.

GUI, B. (2005): "From transactions to encounters: the joint generation of relational goods and conventional values", Economics and social interaction: Accounting for interpersonal relations, 23-51.

HARDIN, G. (1968): "The Tragedy of Commons", Science, 162, 1243-1248.

HERRERO, Y. (2011): "Propuestas eco-feministas para un sistema cargado de deudas", Revista de Economía Crítica, 13, 30-54.

HERRERO, Y. (2012): "Perspectivas ecofeministas para la construcción de una economía compatible con una vida buena", En: Sostenibilidad de la vida. Aportaciones desde la Economía Solidaria, Feminista y Ecológica, REAS, Red de Economía Alternativa y Solidaria de Euskadi, 55-68.

HOLLENBANCH, D. (2002): The Common Good and Christian Ethics, Cambridge: Cambridge University Press.

KYMLICKA, W. (1995): Filosofía política contemporánea. Una introducción, Ariel, Barcelona.

LATOUCHE, S. (1991): La Planète des naufragés, La Découverte, Paris.

LATOUCHE, S. (2009): Pequeño Tratado del Decrecimiento Sereno, Icaria, Barcelona.

LAVILLE, J. (Dir.) (1994): L'économie solidaire; une perspective internationale, Paris: Desclée de Brouwer.

LAVILLE, J.L. (Ed.) (2004): Economía social y solidaria. Una visión europea, Buenos Aires, Fundación OSDE -Universidad Nacional de General Sarmiento- Editorial Altamira.

LAVILLE, J.L. \& GARCÍA, J. (2009): Crisis capitalista y Economía Solidaria, Barcelona, Icaria.

MARTíNEZ, A. \& ÁLVAREZ, S. (2008): "La economía crítica y solidaria: perspectivas teóricas y experiencias para la construcción de una economía alternativa". En: La situación del mundo 2008. Innovaciones para una economía sostenible, Informe anual del Orldwatch Institute sobre el Progreso hace una Sociedad Sostenible, Barcelona: CIP-Ecosocial e Icaria, 371-486.

MAX-NEEF, M. (1994): Desarrollo a escala humana: Conceptos, aplicaciones y reflexiones, Icaria Editorial, Barcelona, España.

MONZÓN, J.L. (2003): "El cooperativismo en la historia de la literatura económica", CIRIEC-España, Revista de Economía Pública, Social y Cooperativa, 44, 9-32.

MONZÓN, J.L. (2006): "Economía Social y conceptos afines, fronteras borrosas y ambigüedades conceptuales del Tercer Sector", CIRIEC-España, Revista de Economía Pública, Social y Cooperativa, 56, 9-24. 
MONZÓN, J.L. (2013): "La Economía Social desde la perspectiva Europea". En: Oulhaj, L. (Coord): Miradas sobre la economía social y solidaria en México, Co-Unidad Universitaria del Golfo Centro, México, 75-89.

MONZÓN, J.L. \& CHAVES, R. (2012): La economía social en la Unión Europea, Comité Económico y Social Europeo, Bruselas.

NAREDO, J.M. (2003): La Economía en Evolución. Historia y Perspectivas de las categorías del pensamiento económico, S. XXI, Madrid.

NORTH, D.C. (1990): Institutions, Institutional Change and Economic Performance, Cambridge: Cambridge University Press.

NUSSBAUM, M.C. (1986): The Fragility of Goodness. Luck and Ethics in Greek Tragedy and Philosophy, Cambridge, Cambridge University Press.

OSTROM, E. (1998): "A behavioural approach to the rational choice theory of collective action", American Political Science Review, 1 (92), 1-22.

OSTROM, E. (2003): "Toward a behavioral theory linking trust, reciprocity and reputation". In: Trust and reciprocity. Interdisciplinar lessons from experimental research, Department of Sociology, University of Oxford.

OUID AHMED (2015): "What does 'solidarity economy' mean? Contours and feasibility of a theoretical and political project", Business Ethics: A European Review, 24 (2), 425-435.

PARLAMENTO EUROPEO (2009): Resolución del Parlamento Europeo, de 19 de febrero de 2009, sobre economía Social, http://www.europarl.europa.eu/

PÉREZ DE MENDIGUREN, ETXEZARRETA \& GURIDI (2012): "Economía Social, Empresa Social y Economía Solidaria: diferentes conceptos para un mismo debate", Papeles de Economía Solidaria, $1,7-38$

PÉREZ DE MENDIGUREN, J.C. \& ETXERRETA, E. (2015): "Sobre el concepto de economía social y solidaria: aproximaciones desde Europa y América Latina", Revista de Economía Mundial, 40, 123-143.

POLANYI, K. (2007): La gran trasformación. Los orígenes políticos y económicos de nuestro tiempo, Fondo de Cultura Económica, Buenos Aires.

PORTER, M.E. \& KRAMENER, M.R. (2011): "Creating shared value", Harvard Business Review, 89 $(1 / 2), 62-77$.

RAUBEN, I. (2006): Sujetos Políticos. Rumbos estratégicos y tareas actuales de los movimientos sociales y políticos, Sango Domingo, República Dominicana, Editorial Pasado y Presente XXI, disponible en: http://es.scribd.com/doc/77913529//sabel-Rauber-Sujetos-Politicos

RAZETO, L. (1984): Economía de Solidaridad y Mercado Democrático, Ediciones PET, Santiago.

RAZETO, L. (2015): Tópicos de Economía Comprensiva, Ediciones Univérsitas Nueva Civilización, Santiago de Chile. 
RED DE ECONOMÍA ALTERNATIVA Y SOLIDARIA (2015): Auditoria Social, https://madrid.mercadosocial.net/balance.php

RED DE ECONOMÍA ALTERNATIVA Y SOLIDARIA: Carta de principios, http://economiayderechos.observatoridesc.org/economia-solidaria-y-derechos-humanos/principios

RIPPES (2013): Carta de la Economía Solidaria, http://www.ripess.org/wp-content/uploads/2013/06/DOC3_global_vision_RIPESS_Char_ES.pdf

ROEMER, J.E. (2012): "On several approaches to equality of opportunity", Economics and Philosophy, 28(02), 165-200.

SANDEL, M. (1982): Liberalism and the Limits of Liberty, Cambridge University Press, Cambridge.

SANTOS, B.S. \& GARAUTI, C.A.R. (2007): "Para ampliar el canon de la producción", Otra Economía, $1(2), 8-13$.

SASIA, P. (2012): "La Banca Ética en Europa: el enfoque del crédito como criterio de configuración de un espacio de alternativa", CIRIEC-España, Revista de Economía Pública, Social y Cooperativa, $75,277-299$.

SEN, A. (1981): "Development: Which Way Now?", Economic Journal, 93, 745-62.

SEN, A. (1999): Development as Freedom, Nueva York: Knopf.

SINGER, P. (2009): "Relaciones entre sociedad y Estado en la economía solidaria", Íconos: Revista de Ciencias Sociales, 33, 51-65.

SISODIA, R. (2011): "Conscious Capitalism: A Better Way to Win", California Management Review, 53:3, 98-108.

STIGLITZ, J.E., SEN, A. \& FITOUSSI, J.P. (2013): Medir nuestras vidas, RBA Libros.

STRADA RODRÍGUEZ, J. (2012): "Debates al interior de la economía social: la reconfiguración neoliberal y la visión regeneradora de las políticas sociales", Papeles de Trabajo, 24, Diciembre, Centro de Estudios Interdisciplinarios en Etnolingüística y Antropología Socio-Cultural, 49-72.

UHLANER, C.J. (1989): "Relational goods and participation: Incorporating sociability into a theory of rational action", Public choice, 62 (3), 253-285.

VÁZQUEZ, B. (2000): Desarrollo económico local y descentralización: aproximación a un marco conceptual proyecto CEPAL/GTZ. Desarrollo económico local y descentralización en América Latina. Santiago de Chile, CEPAL.

VILLASANTE, T.R. (1995): Las democracias participativas, HOAC, Madrid.

ZAMAGNI, S. (2012): Por una economía del bien común, Ciudad Nueva.

ZAMAGNI, S. \& BRUNI, L. (2007): Economia civile: efficienza, equità, felicità pubblica, II Mulino, Bologna. 